\title{
RESERVAS INTERNACIONAIS ÓTIMAS PARA O BRASIL: UMA ANÁLISE SIMPLES DE CUSTO-BENEFÍCIO PARA O PERÍODO 1999-2007*
}

\author{
Marco Antônio F. de H. Cavalcanti ${ }^{\S}$ \\ Christian Vonbun
}

\begin{abstract}
RESUMO
Este artigo calcula, por meio de extensões da metodologia de Ben-Bassat e Gottlieb (1992), o nível ótimo de reservas internacionais para o Brasil no período 1999-2007, bem como as perdas sociais associadas à manutenção de reservas em nível distinto do ótimo. De acordo com os resultados obtidos, o nível de reservas observado no Brasil parece ter se tornado "excessivo" a partir de 2005 ou 2006, sob diversos cenários e hipóteses alternativas para os principais parâmetros do modelo, gerando perdas sociais crescentes para o País.
\end{abstract}

Palavras-chave: reservas internacionais, dívida externa, crises de default.

\section{ABSTRACT}

This paper calculates the optimal level of foreign reserves for Brazil during 1999-2007, by applying various extensions of the Ben-Bassat and Gottlieb (1992) framework. We also estimate the social loss due to differences between actual and optimal reserves holdings by the Brazilian Central Bank. Our results suggest that, under various alternative scenarios and hypotheses regarding the model's main parameters, the actual level of reserves in Brazil has become "excessive" around 2005-2006, thereby generating high and increasing costs for the Brazilian economy.

Keywords: optimal international reserves, foreign debt, default crises.

JEL classification: E63, F31, F32, F34, F40, F41, G11.

* Os autores agradecem a Daniel Gottlieb, Manoel Carlos de Castro Pires, Marcelo de Sales Pessoa, José Ronaldo de Castro Souza Jr. e João Luís Mendonça por diversas contribuições ao longo do trabalho, e a Fernando Gonçalves por valiosos comentários.

$\S \quad$ IPEA - Instituto de Pesquisa Econômica Aplicada. Endereço para contato: Av. Pres. Antonio Carlos, 51/1407. CEP: 20020-010 - Rio de Janeiro - RJ. Email: marco.cavalcanti@ipea.gov.br.

a IPEA - Instituto de Pesquisa Econômica Aplicada. Endereço para contato: Av. Pres. Antonio Carlos, 51/1417. CEP: 20020-010 - Rio de Janeiro - RJ. Email: christian.vonbun@ipea.gov.br.

Recebido em novembro de 2007. Aceito para publicação em junho de 2008. 


\section{INTRODUÇÃO}

Entre meados de 2006 e meados de 2007, o volume de reservas internacionais do Brasil cresceu a um ritmo acelerado, passando de cerca de US $\$ 60$ bilhões no segundo trimestre de 2006 para mais de US $\$ 162$ bilhões em setembro de 2007. O crescimento das reservas se deu tanto em termos absolutos como relativos; conforme mostram as Gráficos 1 e 2, as razões reservas/PIB, reservas/importações e reservas/dívida externa de curto prazo aumentaram significativamente no período, atingindo seus maiores níveis no período de câmbio flutuante.

Gráfico 1 - Reservas internacionais brasileiras, em relação ao PIB e às importações totais do País: jan/1995-set/2007

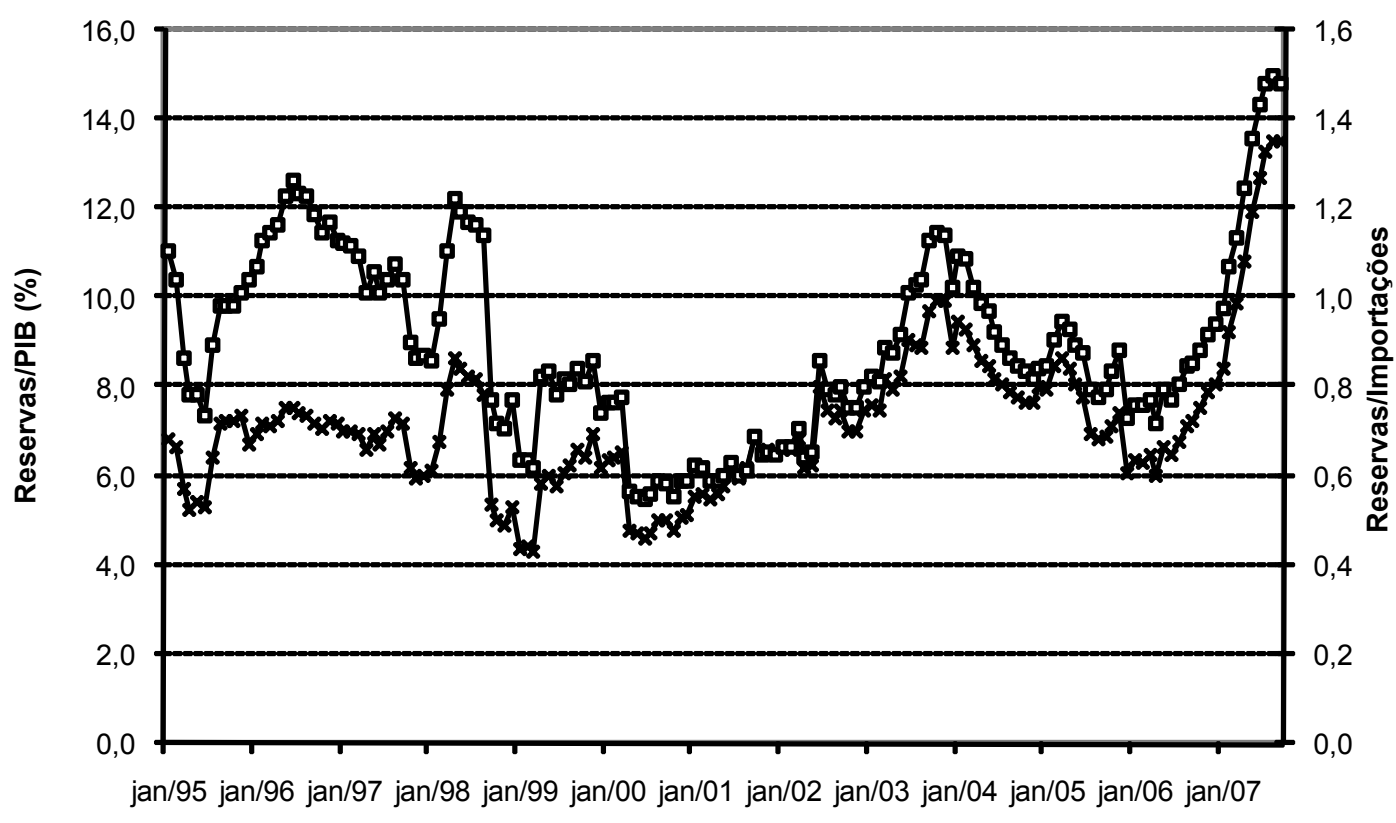

*-Reservas/PIB (\%) $\rightarrow$ - Reservas/lmportações acumuladas em 12 meses

Obs.: Reservas internacionais - conceito liquidez

Fonte: Banco Central do Brasil.

Esta massiva acumulação de reservas internacionais pelo Banco Central do Brasil tem gerado intenso debate entre os economistas: na opinião de alguns, o volume corrente de reservas seria importante e necessário como um "seguro" contra crises internacionais ou como forma de evitar a apreciação do Real, enquanto que, na opinião de outros, o nível de reservas seria "ex- 
cessivo” e estaria impondo um custo desnecessário ao País, associado ao custo de carregamento das reservas. ${ }^{1}$

É importante ressaltar que a forte acumulação de reservas internacionais no período recente não é exclusividade do Brasil. De fato, a partir da segunda metade da década de 1990, esse fenômeno foi verificado em diversos países emergentes, tendo suscitado a curiosidade de vários pesquisadores interessados em investigar se os níveis de reservas observados nesses países seriam "adequados” ou "excessivos”. De modo geral, os estudos desenvolvidos até o momento parecem indicar que a acumulação de reservas observada em vários países emergentes tem sido realmente excessiva (JEANNE, 2007).

Gráfico 2 - Reservas internacionais brasileiras/dívida externa de curto prazo (\%): $4^{\circ}$ tri/1995 $2^{\circ}$ tri $/ 2007$

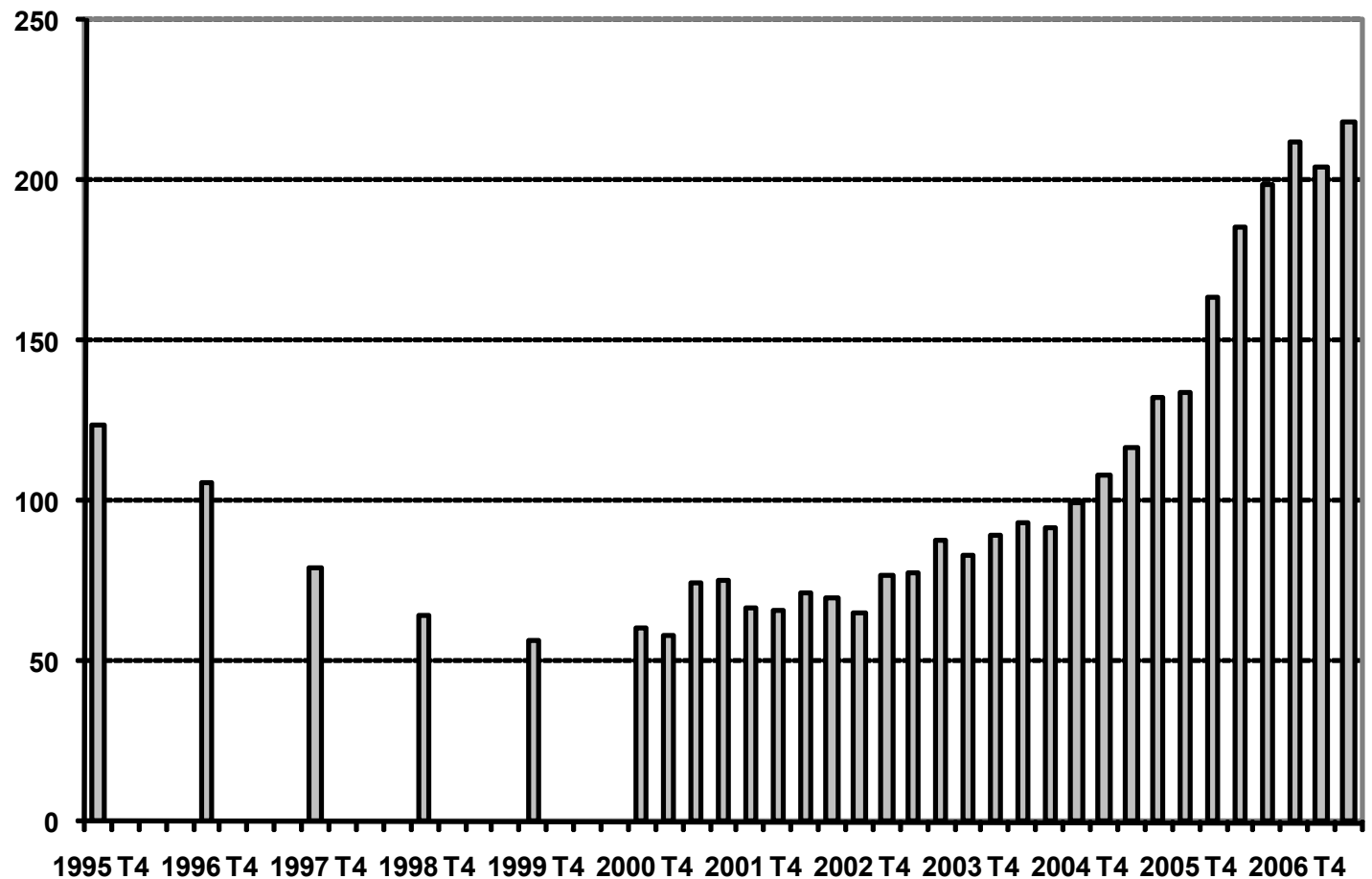

Obs.1: Reservas internacionais - conceito liquidez

Obs. 2: Até 2000, dados disponíveis apenas para o final do ano.

Fonte: Banco Central do Brasil.

No Brasil, a percepção de que as reservas internacionais teriam ultrapassado um nível “ótimo” parece corroborada pelo fato de que as razões reservas/importações e reservas/dívida

1 Ver, por exemplo, Barenboim (2006, 2007), Garcia (2006a,b; 2007), Loyola (2006), Pastore e Pinotti (2007), Barbosa (2007), Haddad (2007), Lacerda (2007), Oreiro e Curado (2007) e a entrevista com Eduardo Loyo no Valor Econômico de 16/08/2007. 
externa de curto prazo, usadas freqüentemente como indicadores de adequação do nível de reservas, apresentam valores muito acima de níveis julgados "seguros". De um lado, o coeficiente reservas/importações, atualmente em torno de 1, é elevado não apenas em relação ao critério tradicional, segundo o qual as reservas deveriam cobrir pelo menos 3 meses de importações - o que corresponderia a um coeficiente da ordem de 0,25 -, mas também em relação aos valores de 0,55 e 0,67, julgados adequados, de acordo com a análise de Nitithanprapas e Willet (2002), para países com regimes cambiais de flutuação livre e suja, respectivamente. De outro lado, o coeficiente reservas/dívida externa de curto prazo encontra-se atualmente em torno de 2, que corresponde ao dobro do valor considerado adequado segundo a regra de bolso de GuidottiGreenspan. $^{2}$

Cabe notar que os níveis de reservas no Brasil parecem elevados também em uma perspectiva internacional. De fato, a Tabela 1 mostra que, no terceiro trimestre de 2007, a razão reservas/importações observada no Brasil era a quarta maior, de uma amostra de 31 países emergentes, e apresentava a terceira maior variação porcentual em relação ao final de 2005.

Entretanto, uma discussão séria do nível adequado de reservas para o Brasil não pode estar baseada nos indicadores acima, caracterizados por fraco embasamento teórico e empírico, e requer uma análise mais cuidadosa dos possíveis custos e benefícios associados à manutenção de reservas internacionais pelo País. Nesse sentido, conforme ressaltado por um dos economistas que tem abordado a questão, o debate “carece de números”. De fato, são raros os estudos quantitativos que confrontam, para o Brasil, os custos e benefícios associados às reservas, e nenhum deles analisa o período recente de forte acumulação de reservas. O objetivo deste artigo é contribuir para esse debate, por meio da estimação do nível "ótimo” de reservas internacionais para o Brasil no período 1999-2007, a partir de uma análise simples de custo-benefício.

A análise baseia-se no modelo desenvolvido por Ben-Bassat e Gottlieb (1992) - doravante $\mathrm{BG}$-, que leva em consideração alguns dos principais custos e benefícios que, segundo a literatura, estariam associados à manutenção de reservas internacionais por certo país. No modelo original de $\mathrm{BG}$, o benefício proporcionado pelas reservas diz respeito à maior capacidade de prevenção de "crises de default": quanto maior o volume de reservas, menor a probabilidade de default sobre as obrigações externas do país e, portanto, menor a probabilidade de o país incorrer na perda de produto associada a um "colapso cambial”. Por outro lado, a retenção de riqueza sob a forma de reservas internacionais apresenta um custo de oportunidade, dado pela diferença entre a taxa de juros obtida pela aplicação das reservas no mercado financeiro internacional - geralmente, em títulos do Tesouro norte-americano - e a taxa de retorno que poderia ser obtida pela aplicação de tais recursos em investimentos alternativos, possivelmente mais rentáveis do ponto de vista social - por exemplo, no aumento do investimento agregado da economia ou na amortização da dívida externa do país. O nível ótimo de reservas é aquele que minimiza a função de perda das autoridades monetárias, na qual tais benefícios e custos são considerados explicitamente.

2 Para uma breve discussão da regra de Guidotti-Greesnpan, ver, dentre outros, Jeanne e Ranciére (2006). 
Tabela 1 - Reservas internacionais para países selecionados, 2005-2007(*)

\begin{tabular}{|c|c|c|c|c|c|c|c|c|}
\hline \multirow[t]{2}{*}{ Países } & \multicolumn{2}{|c|}{2005} & \multicolumn{2}{|c|}{2006} & \multicolumn{2}{|c|}{$2007\left({ }^{\star}\right)$} & \multicolumn{2}{|c|}{ Variação 2007/2005 (\%) } \\
\hline & $\begin{array}{l}\text { Reservas } \\
\text { (US\$ Milhões) }\end{array}$ & $\begin{array}{l}\text { Reservas/ } \\
\text { Importações }\end{array}$ & $\begin{array}{c}\text { Reservas } \\
\text { (US\$ Milhões) }\end{array}$ & $\begin{array}{l}\text { Reservas/ } \\
\text { Importações }\end{array}$ & $\begin{array}{c}\text { Reservas } \\
\text { (US\$ Milhões) }\end{array}$ & $\begin{array}{l}\text { Reservas/ } \\
\text { Importações }\end{array}$ & Reservas & $\begin{array}{l}\text { Reservas/ } \\
\text { Importações }\end{array}$ \\
\hline China & $818.872,00$ & 1,24 & $1.066 .340,00$ & 1,35 & $1.433 .610,00$ & 2,22 & 75,07 & 78,55 \\
\hline Rússia & $175.690,00$ & 1,27 & $295.277,00$ & 1,63 & $414.895,00$ & 1,83 & 136,15 & 44,09 \\
\hline Egito & $20.508,00$ & 1,03 & $24.341,00$ & 1,38 & $28.168,00$ & 1,55 & 37,35 & 49,91 \\
\hline Brasil & $53.216,40$ & 0,69 & $85.147,80$ & 0,89 & $162.158,00$ & 1,44 & 204,71 & 110,50 \\
\hline Bolivia & $1.276,68$ & 0,55 & $2.561,22$ & 0,91 & $4.017,53$ & 1,26 & 214,69 & 131,82 \\
\hline Índia & $131.018,00$ & 0,92 & $170.187,00$ & 0,97 & $239.955,00$ & 1,17 & 83,15 & 27,38 \\
\hline Peru & $13.598,90$ & 0,94 & $16.732,40$ & 0,94 & $23.866,50$ & 1,10 & 75,50 & 16,77 \\
\hline Venezuela & $23.454,00$ & 0,98 & $28.933,00$ & 0,86 & $20.705,00$ & 1,03 & $-11,72$ & 6,00 \\
\hline Argentina & $22.742,00$ & 0,79 & $30.420,90$ & 0,89 & $41.071,90$ & 0,99 & 80,60 & 25,27 \\
\hline Paquistão & $9.816,97$ & 0,39 & $11.327,60$ & 0,38 & $14.509,60$ & 0,97 & 47,80 & 150,00 \\
\hline Marrocos & $16.008,00$ & 0,82 & $20.182,10$ & 0,90 & $23.131,00$ & 0,86 & 44,50 & 4,87 \\
\hline $\begin{array}{l}\text { Coréia do } \\
\text { Sul }\end{array}$ & $209.968,00$ & 0,80 & $238.388,00$ & 0,77 & $256.848,00$ & 0,76 & 22,33 & $-4,92$ \\
\hline Malásia & $69.369,00$ & 0,61 & $81.723,60$ & 0,62 & $97.524,90$ & 0,70 & 40,59 & 14,78 \\
\hline Uruguai & $3.067,80$ & 0,79 & $3.084,17$ & 0,65 & $3.533,64$ & 0,66 & 15,18 & $-16,25$ \\
\hline Colômbia & $14.206,00$ & 0,67 & $14.673,00$ & 0,56 & $19.729,00$ & 0,63 & 38,88 & $-5,89$ \\
\hline Cingapura & $115.712,00$ & 0,58 & $135.813,00$ & 0,57 & $152.018,00$ & 0,61 & 31,38 & 4,96 \\
\hline Jordânia & $5.249,50$ & 0,50 & $6.720,40$ & 0,59 & $7.419,60$ & 0,59 & 41,34 & 18,58 \\
\hline Tailândia & $50.502,00$ & 0,43 & $65.147,10$ & 0,51 & $78.579,90$ & 0,59 & 55,60 & 37,19 \\
\hline Indonésia & $32.925,50$ & 0,44 & $40.866,00$ & 0,51 & $50.920,00$ & 0,57 & 54,65 & 31,05 \\
\hline Israel & $27.839,00$ & 0,59 & $29.011,00$ & 0,58 & $29.104,00$ & 0,52 & 4,54 & $-12,19$ \\
\hline Filipinas & $15.800,10$ & 0,34 & $19.891,40$ & 0,37 & $27.731,10$ & 0,50 & 75,51 & 47,83 \\
\hline Turquia & $50.402,00$ & 0,51 & $60.710,00$ & 0,45 & $71.578,00$ & 0,46 & 42,01 & $-9,76$ \\
\hline Polônia & $40.486,90$ & 0,40 & $46.107,00$ & 0,37 & $55.616,10$ & 0,37 & 37,37 & $-7,00$ \\
\hline Chile & $16.689,10$ & 0,51 & $19.225,00$ & 0,50 & $16.136,60$ & 0,37 & $-3,31$ & $-27,45$ \\
\hline $\begin{array}{l}\text { Arábia } \\
\text { Saudita }\end{array}$ & $24.074,00$ & 0,40 & $25.971,00$ & 0,37 & $30.018,00$ & 0,35 & 24,69 & $-12,56$ \\
\hline Equador & $1.667,93$ & 0,16 & $1.456,08$ & 0,12 & $2.932,70$ & 0,31 & 75,83 & 88,75 \\
\hline Rep. Tcheca & $29.137,70$ & 0,38 & $31.053,70$ & 0,33 & $32.449,40$ & 0,29 & 11,37 & $-23,15$ \\
\hline México & $73.014,60$ & 0,31 & $75.447,70$ & 0,28 & $81.262,80$ & 0,28 & 11,30 & $-10,09$ \\
\hline Hungria & $18.296,00$ & 0,28 & $21.316,00$ & 0,28 & $23.090,00$ & 0,26 & 26,20 & $-7,48$ \\
\hline Paraguai & $1.140,32$ & 0,30 & $1.531,52$ & 0,25 & $2.104,36$ & n.d. & 84,54 & n.d. \\
\hline Panamá & $1.192,49$ & 0,29 & $1.315,86$ & 0,27 & $1.552,06$ & n.d. & 30,15 & n.d. \\
\hline
\end{tabular}

(*) Os dados de 2007 referem-se ao terceiro trimestre. Para o cálculo da razão reservas/importações, consideram-se as importações acumuladas em 4 trimestres.

Fonte: International Financial Statistics, FMI. 
O modelo de BG é, evidentemente, muito simples, e ignora diversos outros mecanismos por meio dos quais a acumulação de reservas internacionais poderia, no contexto de taxas de câmbio flutuantes, afetar o bem-estar de certo país. Em particular, o modelo não leva em consideração: (i) a possibilidade de que um maior volume de reservas permita atenuar os efeitos adversos de uma "parada súbita" no fluxo de capitais externos para o país; (ii) o possível efeito das reservas sobre seu custo de oportunidade, quando este depende da percepção do "risco-país"; (iii) a possibilidade de utilização das reservas com o objetivo de reduzir o grau de volatilidade da taxa de câmbio, atenuar situações de "desalinhamento cambial" ou, mesmo, de subvalorizar o câmbio; (iv) o papel das reservas como "colateral” para os capitais externos e, portanto, como meio de reduzir o custo de captação de empréstimos externos e de atrair novos investimentos, e (v) o custo fiscal associado à necessidade de esterilizar as reservas - que, em países com problemas de solvência fiscal, podem traduzir-se em taxas de juros mais elevadas e perda de produto. Na análise a seguir, o nível "ótimo" de reservas internacionais para o Brasil é estimado a partir de extensões simples do modelo original de BG, que permitem considerar (ainda que de forma bastante rudimentar) os dois primeiros pontos acima, por meio da endogenização do custo de um default externo - de modo análogo a Garcia e Soto (2006) - e do custo de oportunidade das reservas, caso este dependa da percepção do "risco-país" - conforme proposto em Cavalcanti e Vonbun (2007).

Os resultados obtidos sugerem que a acumulação de reservas internacionais observada no Brasil, no período 1999-2007, pode ser, sob alguns dos cenários analisados, pelo menos parcialmente justificada com base nos benefícios supracitados. Entretanto, com exceção de cenários extremos para a magnitude dos custos de um default e para sua sensibilidade em relação às reservas, o nível observado de reservas sempre se revela "excessivo" no final do período em questão, gerando perdas sociais crescentes para o País. Isso parece indicar que, ainda que a política de acumulação de reservas observada entre 2006 e 2007 possa ser considerada acertada com base em alguns dos cenários descritos, já estaria na "hora de parar de comprar", conforme recomendado por Haddad (2007).

É importante ressaltar que a análise desconsidera pelo menos três questões potencialmente relevantes para o cálculo do nível “ótimo” de reservas - o possível uso da política de reservas internacionais como forma de (tentar) afetar a taxa de câmbio, o papel das reservas como "colateral" para investimentos externos e a existência de custos fiscais associados à necessidade de esterilizar as reservas -; logo, a análise é incompleta e seus resultados devem ser interpretados com cautela. Em particular, o "excesso" de reservas observado recentemente no Brasil em relação ao nível ótimo estimado não implica, necessariamente, que a política adotada pelo Banco Central tenha sido inadequada, mas apenas que uma possível justificativa para tal política não pode basear-se unicamente nos benefícios associados à prevenção ou atenuação dos custos esperados de uma crise externa - devendo passar, possivelmente, pela consideração dos benefícios relativos à condução da política cambial ou à atração de novos investimentos externos. A análise rigorosa dessa questão requer, contudo, um esforço considerável, devendo estar baseada em um modelo que incorpore as relações de equilíbrio geral na economia e as várias inter-relações en- 
tre as políticas monetária, fiscal e cambial. Pretende-se, em artigo futuro, construir um modelo que permita investigar tais questões adequadamente.

Este artigo está composto por 6 seções, incluindo esta introdução. A Seção 2 apresenta uma breve revisão da literatura teórica e empírica sobre o nível ótimo de reservas cambiais. A Seção 3 apresenta e discute o modelo teórico a ser utilizado no cálculo das reservas ótimas para o Brasil. A Seção 4 discute a estimação dos parâmetros relevantes do modelo, a partir de dados para o período 1999-2007. A Seção 5 apresenta os níveis ótimos de reservas calculados para o Brasil no período em questão, e discute as implicações de política dos resultados obtidos. A Seção 6 reúne as conclusões do trabalho.

\section{RESERVAS INTERNACIONAIS ÓTIMAS: REVISÃO DA LITERATURA}

\subsection{Literatura internacional}

A literatura acerca das reservas internacionais ótimas remonta à década de 1960. O esforço seminal de Heller (1966) foi o primeiro a incorporar o conceito de otimização ao problema da determinação da demanda por reservas, debate anteriormente dominado por "índices de adequação" ad hoc. O contexto da época, caracterizado por pouca mobilidade de capitais e taxas de câmbio controladas, implicava que os maiores desequilíbrios nas contas externas dos países advinham das transações comerciais, e que as reservas deviam servir, assim, como "buffers" para amortecer os desequilíbrios do balanço de pagamentos. Isso levou Heller a incorporar a seu modelo, ainda que de forma rudimentar, variáveis ligadas ao comércio, como o tamanho de um país e sua propensão a importar, além de um abstrato "custo de ajustamento" e da taxa social de retorno ao capital, para servir como custo de oportunidade das reservas. $\mathrm{O}$ artigo foi seguido por contribuições de Kenen e Yudin (1965) - que introduziram o uso de técnicas econométricas na discussão do tema - e de Machlup (1966).

O uso de técnicas econométricas estimulou o aparecimento de uma linha de pesquisa correlata, exemplificada por Clark (1970), que buscava entender os determinantes da demanda por reservas internacionais. ${ }^{3}$ Nessa literatura, que ganhou proeminência entre o final da década de 1960 e início da década de 1970, era comum o uso de variáveis explicativas ligadas ao tamanho da economia, além da variabilidade do balanço de pagamentos, da razão reservas/importações e da propensão marginal a importar.

Com o colapso do sistema de Bretton Woods no início dos anos de 1970, o tema ganhou novo fôlego. Afinal, ao contrário do que previam os modelos macroeconômicos então predominantes, grande parte dos países que passaram a adotar o regime de câmbio flutuante continuaram a manter volumes significativos de reservas internacionais - o que exigia explicações teóricas e empíricas convincentes. A seguinte passagem de Heller e Kahn (1978) ilustra esse ponto:

3 Bahmani-Oskoee (1985) e Bahmani-Oskoee e Brown (2002) apresentam interessantes resenhas sobre o tema. 
A visão padrão de livro-texto, recentemente ecoada por Harberler (1977), argumenta que em um sistema de câmbio flutuante, a necessidade de um país manter reservas internacionais desaparece, já que desequilíbrios no balanço de pagamentos serão corrigidos por movimentos em sua taxa de câmbio. A despeito dessa visão, é notório que, sob o sistema cambial corrente, os países não apenas continuaram a manter reservas internacionais, mas também, em alguns casos, elevaram seu montante. ${ }^{4}$

Esse conflito entre teoria e evidência empírica deu origem a diversos estudos visando analisar a estabilidade da função de demanda por reservas em face da mudança do regime cambial - que claramente se contrapunha à visão tradicional. Segundo vários autores, dentre os quais Heller e Kahn (1978), Saidi (1981), Edwards (1983), Frenkel (1980a, b; 1983), Lizondo e Mathieson (1987) e Bahmani-Oskoee (1988), a função demanda de reservas realmente sofrera uma quebra estrutural na transição para o câmbio flutuante, sob a forma de um deslocamento à esquerda dessa função, o que de certa forma reforçava a visão padrão. Outros autores, porém, encontraram estabilidade na função de demanda por reservas mesmo após a ruptura das paridades cambiais - ver, por exemplo, Crockett (1978) e Huang (1995).

De toda forma, a maioria dos países continuou mantendo montantes positivos de reservas após a flutuação de suas respectivas moedas - ainda que em quantidades menores do que as observadas anteriormente -, o que por si só contrariava os modelos tradicionais. Conforme observado por Frenkel (1980a), "o tamanho da mudança não foi tão drástico quanto o esperado". Na mesma linha, Heller e Kahn (1978) afirmaram que "a alteração não foi repentina e parece ter ocorrido ao final de 1973, e não na parte inicial do ano, quando a mudança em direção ao regime de câmbio flutuante ocorreu (...) No que concerne aos países em desenvolvimento não produtores de petróleo, o movimento em direção à maior flexibilidade nas taxas de câmbio não pareceu afetar seu comportamento de maneira significativa".

Na década de 1980, o tema perdeu importância, tendo sido abordado por número relativamente restrito de autores. Frenkel e Jovanovich (1981) desenvolveram um modelo de reservas ótimas baseado no papel das reservas como "buffers". Nesse artigo, bem como em Frenkel (1980b), os autores procuraram testar algumas variáveis explicativas para a demanda por reservas, encontrando evidências em favor da variabilidade no balanço de pagamentos e economias de escala na manutenção de reservas. Edwards (1983), contudo, mostrou que países em desenvolvimento obtinham pouca ou nenhuma economia de escala por manter reservas. Lizondo e Mathieson (1987) re-estimaram os modelos de Heller e Kahn (1978), revisaram e estenderam Frenkel (1983), corroborando a inexistência de economias de escala.

Na década de 1990, a manutenção de elevados estoques de reservas e o advento das crises cambiais do Sistema Monetário Europeu, do México e da Ásia reavivaram o interesse na discussão das reservas internacionais. Isso ocorreu em conjunto com o ressurgimento da literatura sobre crises cambiais, cuja "primeira geração" de modelos, instituída por Krugman (1979) e

4 Heller e Kahn (1978p. 623. Tradução nossa.

5 Frenkel, 1980,p. 301. Tradução nossa.

6 Heller e Kahn,1978, p. 644. Tradução nossa. 
Flood e Garber (1984), ressaltava o papel das reservas como mecanismo de adiar crises. A partir dos modelos de crises cambiais de "segunda geração", inaugurados por Obstfeld (1994), e de "terceira geração", exemplificados por Furman e Stiglitz (1998), as reservas ganharam papel ainda mais destacado na prevenção e mitigação dos custos de fugas de capitais.

Nesse contexto, surgiram novos modelos de determinação de reservas ótimas, com destaque para o de Ben-Bassat e Gottlieb (1992) - BG -, que contrastava o benefício proporcionado pelas reservas, referente à maior capacidade de prevenção de "crises de default", ao custo de oportunidade de reter riqueza sob a forma de reservas internacionais, dado pela diferença entre a taxa de juros obtida pela aplicação das reservas no mercado financeiro internacional e a taxa de retorno sobre o capital no país. Esse artigo motivou diversas aplicações empíricas, incluindo Oliveros e Varela (1994), Blanco e Córdoba (1996), Vimolchalao (2003), GIE (2004), García e Soto (2006), Ozyildirim e Yaman (2005) e Angaríta (2006). Entretanto, esses artigos não seguiam à risca a metodologia de BG e usavam como custo de oportunidade das reservas a proxy sugerida por Edwards (1985), isto é, o spread entre a taxa de juros sobre a dívida externa e a taxa de remuneração das reservas. Conforme ressaltado por Cavalcanti e Vonbun (2007), nesse caso, o custo de oportunidade das reservas deveria ser tratado como endógeno em relação às reservas, o que era ignorado pelas aplicações em questão - levando a estimativas viesadas do nível ótimo de reservas. A extensão do modelo de BG para o caso de um custo de oportunidade endógeno foi apresentada em Cavalcanti e Vonbun (2007).

Dentre as limitações da análise de BG, cabe destacar que, em seu modelo, as reservas cambiais contribuíam apenas para prevenir crises, e não para mitigá-las. Apesar de não haver consenso a respeito da capacidade estabilizadora das reservas, ${ }^{7}$ seu papel na prevenção e mitigação de crises tem sido ressaltado na literatura recente que analisa o impacto de "paradas súbitas" na entrada de capitais externos ("sudden stops") sobre os países emergentes. Nesse contexto, Garcia e Soto (2006) estenderam o modelo de BG para o caso de um custo de default externo "endógeno” (em relação às reservas). Jeanne e Ranciére (2006) desenvolveram um modelo microfundamentado de determinação de reservas ótimas, no qual maior volume de reservas permite atenuar os efeitos adversos de uma "parada súbita” no fluxo de capitais externos para o país.

Lopes (2005) monta um modelo que permite que o estoque de reservas impacte, via expectativas, o fluxo de capitais. $\mathrm{O}$ modelo sugere que as reservas reduzem a probabilidade de ocorrência de crises, mas que estas apresentam um efeito colateral: uma vez que as crises se iniciam, elas tendem a se tornar mais profundas. Empiricamente, as reservas se mostraram positivamente correlacionadas à saída de capital nas crises, mas não foram encontrados efeitos das reservas sobre a probabilidade ou sobre os custos de crises. $\mathrm{O}$ artigo não define um nível ótimo de reservas e contribui para enfraquecer a noção de que as reservas são necessárias para assegurar proteção contra reversões de fluxos de capitais.

7 Por exemplo: Calvo, Izquierdo e Mejía (2004) não encontraram evidências de que as reservas impactem o risco de sudden stops, enquanto Edwards (2004) conclui que as reservas são relevantes para explicar a ocorrência deste tipo de crise. Garcia e Soto (2006) argumentam que as reservas reduzem a probabilidade de crise, mas geram um problema de risco moral que pode aprofundar esses eventos. Lopes (2005) apresenta interessante resenha acerca das literaturas de reservas cambiais e de sudden stops. 
Perante o movimento explosivo de acumulação de reservas nos últimos anos, notadamente nos países asiáticos, o interesse no tema das reservas ótimas tem permanecido forte. A literatura recente tem tido como principais objetivos: (i) identificar/testar possíveis canais por meio dos quais as reservas internacionais podem beneficiar um país, e (ii) verificar se, à luz desses mecanismos, os níveis de reservas observados nos países emergentes parecem, ou não, "excessivos". De modo geral, os estudos desenvolvidos até o momento parecem sugerir que a acumulação de reservas observada em vários países emergentes tem sido realmente excessiva. Flood e Marion (2002), por exemplo, conseguiram encontrar nos fundamentos explicação para apenas $15 \%$ da variação das reservas internacionais. Wyplosz (2007) cita uma "massiva acumulação de reservas internacionais", iniciada em meados dos anos de 1990 e que teria ainda se acelerado nos anos recentes. $\mathrm{O}$ autor considera o fenômeno bastante difundido, à exceção dos países desenvolvidos e da América Latina. O artigo estuda a possibilidade de que essa acumulação seria excessiva, concluindo que parte dela decorre do que Dooley et al. (2005) chamam de "motivos mercantilistas".

Aizenman e Lee (2007) começam com um apanhado dos principais motivos para se manter reservas internacionais. O primeiro destes motivos seria o "auto-seguro", isto é, uma demanda precaucionária: a liquidez internacional pode reduzir a probabilidade de uma perda de produto em função de uma fuga de capitais ou minimizar o impacto real de um sudden stop. Além disso, as reservas poderiam ser entendidas como um "colateral" para o investimento estrangeiro, conforme em Dooley et al. (2005). Ainda que não citadas diretamente no artigo, ficam subentendidas as funções de possibilitar a flutuação suja, de modo a estabilizar as cotações cambiais - ou sustentá-las, no caso dos países com paridades cambiais fixas -, bem como de reduzir o custo de captação de empréstimos externos, o que está ligado à função de colateral supracitada. Retomando a idéia de Dooley et al. (2005), o artigo reforça a importância do que denomina "mercantilismo monetário", 8 que seria o acúmulo de reservas para evitar uma apreciação cambial e, desta forma, manter a competitividade das exportações em terceiros mercados, notadamente no dos EUA. Dentre os principais insights do artigo, cabe destacar a relação entre custos fiscais e políticas "mercantilistas": países com custos fiscais (de esterilização) mais baixos teriam maior capacidade de promover a subvalorização de suas moedas e, portanto, maior incentivo a acumular reservas; a China, nos dias de hoje, seria um possível exemplo.

\subsection{Aplicações para o Brasil}

A literatura sobre reservas cambiais ótimas para o Brasil é surpreendentemente escassa. Isso é ainda mais notável quando se observam intensas discussões acerca da política de reservas do Banco Central, tanto na imprensa como em debates e seminários. A seguir, são discutidas brevemente as principais aplicações recentes sobre o tema.

Silva Jr. et al.(2004) identificam um efeito de realimentação entre o volume e o perfil da dívida pública e o nível de reservas cambiais, por meio de um modelo de controle estocástico ótimo, no qual a acumulação de reservas seria usada para reduzir o risco de uma crise de de-

8 Em contraposição ao “Mercantilismo Financeiro”, definido por Wyplosz (2002), que se trata de subsidiar o investimento interno, inclusive por meio da manutenção da poupança interna no sistema financeiro doméstico. 
fault em momentos de deterioração de outros fundamentos. A compra ou venda de reservas é, portanto, considerada endógena em relação às necessidades de se controlar os riscos da dívida e aos objetivos da política monetária. Por meio da utilização do modelo de Frenkel e Jovanovich (1981), os autores determinam o nível adequado de reservas no período entre janeiro de 1999 e agosto de 2004, chegando a resultados que sugerem que, a partir da segunda metade de 2002, as reservas brasileiras passaram a estar acima do ideal, na maior parte do tempo. Um ponto interessante do artigo é que a política de minimização de riscos da dívida deve incluir intervenções no mercado de câmbio, implicando a necessidade de adoção de um regime de flutuação suja, com conseqüente acumulação de reservas. É importante notar que a disponibilidade de reservas em volume maior (menor) que o adequado permitiria a adoção de taxas de juros menores (maiores).

Silva e Silva (2004) também empregam o modelo de Frenkel e Jovanovich (1981), calculando o estoque ótimo de reservas para o Brasil no período entre janeiro de 1995 e março de 2004 em função do desvio padrão do resultado do balanço de pagamentos, do custo de ajustamento do nível de reservas, do total de importações e do custo de oportunidade das reservas - definido como uma média ponderada da diferença entre o retorno das reservas e os custos das dívidas externa e interna. ${ }^{9}$ De acordo com seus resultados, as reservas observadas encontravam-se abaixo do nível ótimo antes da desvalorização de janeiro de 1999; entre 1999 e 2004, sucederam-se períodos de "sobreacumulação" e de "subacumulação" de reservas, e, a partir de março de 2004, o País já possuía mais reservas do que o considerado ótimo.

Finalmente, Cavalcanti e Vonbun (2007) apresentam estimativas do nível ótimo de reservas para o Brasil no período 1999-2006, a partir de aplicações do modelo BG original e de sua extensão para o caso de um custo de oportunidade "endógeno". Dado o foco metodológico do artigo, a discussão da aplicação empírica ao caso brasileiro é breve e incompleta. De qualquer forma, os resultados obtidos são sugestivos. De acordo com o modelo BG original, as reservas observadas no País encontravam-se, sob diversos cenários para a magnitude dos custos de uma crise de default, abaixo do nível ótimo até 2003-2004, tendo então ultrapassado o nível ótimo e se tornado crescentemente "excessivas" - corroborando, nesse ponto, os resultados de Silva e Silva (2004). Por outro lado, as conclusões a partir do modelo BG "modificado” variavam significativamente entre os cenários considerados: para custos de crise relativamente baixos, as reservas teriam estado acima do nível ótimo ao longo de todo o período analisado, enquanto que, para os cenários mais pessimistas de custos de crises, as reservas observadas teriam estado próximas do ótimo, ou abaixo deste, na maior parte do tempo.

Dentre as limitações do estudo de Cavalcanti e Vonbun (2007) para o debate corrente sobre o nível de reservas para o Brasil, cabe destacar, em primeiro lugar, o fato de que a discussão dos resultados e de suas implicações de política é muito breve - o que é explicado, conforme citado acima, pelo foco metodológico do artigo. Segundo, as estimativas do nível ótimo de reservas param no final de 2006, não permitindo a análise do período mais recente de forte acumulação de reservas no País. Terceiro, a amostra utilizada na estimação de alguns parâmetros cruciais do

9 Os autores também incluem uma variável dummy para a mudança de regime cambial em 1999. 
modelo baseia-se em estimativas do PIB anteriores à significativa revisão das Contas Nacionais realizada pelo IBGE em março de 2007 - requerendo, portanto, uma atualização a partir dos dados revistos. ${ }^{10}$ Por fim, assim como a análise original de BG, o estudo peca por desconsiderar o papel potencial das reservas na mitigação das crises. A análise nas próximas seções busca superar essas limitações.

\section{UM MODELO SIMPLES DE DETERMINAÇÃO DO NÍVEL ÓTIMO DE RESERVAS}

O modelo de determinação das reservas ótimas apresentado a seguir apresenta extensões do modelo desenvolvido originalmente por BG, procurando levar em consideração alguns dos principais custos e benefícios associados à manutenção de reservas internacionais por certo país. No modelo, o custo da retenção de riqueza sob a forma de reservas internacionais diz respeito ao custo de oportunidade desses recursos, dado pela diferença entre a taxa de juros obtida pela aplicação das reservas no mercado financeiro internacional e a taxa de retorno que poderia ser obtida pela aplicação de tais recursos em investimentos alternativos, possivelmente mais rentáveis do ponto de vista social - por exemplo, no aumento do investimento agregado da economia ou na amortização da dívida externa do país. Porém, a manutenção de reservas internacionais também apresenta benefícios.

Supõe-se, de fato, que o país esteja sujeito a "paradas súbitas" no influxo de capitais externos e, portanto, a crises de default ${ }^{11}$ sobre suas obrigações externas, que devem resultar em perda de produto e bem-estar; nesse cenário, as reservas internacionais podem proporcionar dois benefícios básicos para o país: (i) maior capacidade de prevenção das crises de default - pois, quanto maior o volume de reservas, maior a capacidade de responder a ataques especulativos ou paradas súbitas e, portanto, menor a probabilidade de default sobre as obrigações externas do país, e (ii) capacidade de atenuação dos efeitos adversos de uma crise de default, quando esta de fato ocorrer - pois a utilização das reservas deve reduzir a magnitude do ajustamento requerido nos níveis de produto e absorção doméstica.

Além disso, caso o custo de oportunidade de manter reservas esteja associado ao spread entre a taxa de juros paga sobre a dívida externa do país e a taxa de juros recebida pela aplicação das reservas no mercado internacional, maiores volumes de reservas podem gerar um benefício adicional, em termos de redução desse custo de oportunidade - pois é razoável supor que o spread da dívida externa esteja correlacionado positivamente com a probabilidade de default sobre as obrigações externas do país e, conseqüentemente, dependa negativamente do nível de reservas.

10 Além disso, a amostra utilizada nas estimações é bastante curta (93 observações, entre março de 1999 e dezembro de 2006), e a adição de 9 observações adicionais (janeiro-setembro de 2007) pode representar ganhos substanciais em termos de precisão das estimativas.

11 O modelo BG é plenamente coerente com a utilização de reservas como prevenção a crises de defaut, especialmente se o regime cambial for flutuante. O risco-país e os fundamentos utilizados nas regressões são variáveis que ajudam a estimar a probabilidade, ou a percepção da probabilidade deste tipo de crises. Contudo, o modelo pode não estar circunscrito apenas a este tipo de crises, desde que se assuma que a crise é endógena, dependendo dos fundamentos e do volume de reservas. Neste caso, o modelo pode servir como proxy para determinar as reservas ótimas para casos de crises cambiais e de sudden stops. 
O nível ótimo de reservas resolve o seguinte problema de minimização das autoridades monetárias:

$$
\operatorname{Min}_{R} \quad \pi(R) C(R)+(1-\pi(R)) r(\pi(R)) R
$$

onde $R$ é o nível de reservas internacionais, $\pi$ é a probabilidade de uma crise de default, $C$ é o custo esperado de uma crise de default, e $\gamma$ é o custo "unitário" de oportunidade de manter as reservas. Supõe-se que $\pi, C$ e $\gamma$ dependam do nível de reservas em conformidade com as seguintes condições: ${ }^{12}$

$$
\begin{aligned}
& \frac{\partial \pi}{\partial R}=\pi^{\prime}(R)<0 \\
& \frac{\partial C}{\partial R}=C^{\prime}(R) \leq 0 \\
& \frac{\partial r}{\partial R}=r^{\prime}(\pi) \pi^{\prime}(R) \leq 0
\end{aligned}
$$

Vale notar que, quando ambas as condições (2b) e (2c) são satisfeitas como igualdades, obtém-se o modelo original de BG, no qual o custo de uma crise de default, $C$, e o custo de oportunidade de reter reservas, $r$, são "exógenos" - isto é, não dependem do nível de reservas. Quando apenas (2b) é satisfeita como igualdade, obtém-se o modelo com custo de oportunidade endógeno (e custo de default exógeno) analisado em Cavalcanti e Vonbun (2007), e, quando apenas (2c) é satisfeita como igualdade, obtém-se o modelo com custo de default endógeno (e custo de oportunidade exógeno) de Garcia e Soto (2006). No caso mais geral, em que ambas as condições (2b) e (2c) são satisfeitas como desigualdades, ambos os custos de default e de oportunidade são endógenos. Na discussão a seguir, será feita referência a cada um desses casos particulares conforme classificação abaixo:

Caso I - Custo de default exógeno/custo de oportunidade exógeno.

Caso II - Custo de default exógeno/custo de oportunidade endógeno.

Caso III - Custo de default endógeno/custo de oportunidade exógeno.

Caso IV - Custo de default endógeno/custo de oportunidade endógeno.

A condição de primeira ordem para o problema de minimização (1) é:

$$
\pi^{\prime}(R)\left[-R r(\pi(R))+R(1-\pi(R)) r^{\prime}(\pi)+C(R)\right]+(1-\pi(R)) r(\pi(R))+C^{\prime}(R) \pi(R)=0
$$

Rearrumando, obtém-se uma expressão implícita para o nível ótimo de reservas, $R^{*}$ :

12 Omite-se, por simplicidade, a dependência dessas variáveis em relação a outros fatores na exposição a seguir. 


$$
R^{*}=\left[\frac{1-\pi\left(R^{*}\right)}{\pi^{\prime}\left(R^{*}\right)}+\frac{C(R)}{r\left(\pi\left(R^{*}\right)\right)}+\frac{C^{\prime}(R) \pi\left(R^{*}\right)}{r\left(\pi\left(R^{*}\right)\right) \pi^{\prime}\left(R^{*}\right)}\right]\left[\frac{1}{1-\left(1-\pi\left(R^{*}\right)\right)^{r^{\prime}\left(\pi\left(R^{*}\right)\right)}}\right]
$$

Evidentemente, sob o Caso I (custos de default e de oportunidade exógenos), essa expressão corresponde à fórmula original para as reservas ótimas de BG:

$$
R^{*}=\frac{1-\pi\left(R^{*}\right)}{\pi^{\prime}\left(R^{*}\right)}+\frac{C}{r}
$$

Definindo $\delta=\pi /(1-\pi)$, a expressão (4) pode ser reescrita de forma mais conveniente para a implementação prática do modelo, em função das elasticidades de $\delta$ e de $C$ com respeito a $R$ - respectivamente, $\varepsilon_{\delta, R}$ e $\varepsilon_{C, R}$ - e da elasticidade de $r$ em relação a $\pi, \varepsilon_{r, \pi}$ :

$$
R^{*}=\left(\frac{C(R)}{r\left(\pi\left(R^{*}\right)\right)}\right)\left(1+\frac{\varepsilon_{C, R}}{\left(1-\pi\left(R^{*}\right)\right) \varepsilon_{\delta, R}}\right)\left(\frac{\pi\left(R^{*}\right) \varepsilon_{\delta, R}}{\left[\pi\left(R^{*}\right)-\left(1-\pi\left(R^{*}\right)\right) \varepsilon_{r, \pi}\right] \varepsilon_{\delta, R}-1}\right)
$$

As variáveis $R^{*}, \pi, C$ e $\gamma$ são determinadas a partir do sistema formado por (4") e por funções $\pi(R C(R)$ e $\gamma(\pi(R))$ que satisfaçam as condições (2a)-(2c). A estimação empírica dessas funções é discutida na próxima seção.

\section{CENÁRIOS E ESTIMAÇÃo DE PARÂMETROS DO MODELO}

A implementação prática do modelo depende de forma crucial das estimativas das funções $\pi(R C(R)$ e $\gamma(\pi(R))$. Esta seção descreve os procedimentos adotados na estimação dessas funções para o caso brasileiro. Cabe ressaltar que, dada a dificuldade - ou, mesmo, impossibilidade de estimação adequada de algumas dessas funções para o Brasil, optou-se por trabalhar com cenários alternativos, dentro de intervalos julgados "razoáveis", para alguns dos parâmetros relevantes.

\subsection{Estimação de $\pi(\mathbf{R})$}

A estimação de $\pi(R)$ requer, em primeiro lugar, uma estimativa da variável não-observada $\pi$. Supõe-se, em conformidade com BG e Feder e Just (1977), dentre outros, a validade da seguinte relação entre as chances de não-pagamento da dívida externa, $\delta=\pi /(1-\pi)$, e o prêmio de risco descontado, $\left(i_{D}-i_{i}\right) /\left(1+i_{i}\right)$ : 


$$
\delta=\frac{\pi}{(1-\pi)}=\frac{\left(i_{D}-i_{i}\right)}{\left(1+i_{i}\right)}
$$

onde $i_{D}$ é a taxa de juros média sobre a dívida externa do país e $i_{i}$ é a taxa de juros dos títulos de 10 anos do Tesouro dos EUA (usada como proxy para a taxa internacional livre de risco). Para simplificar a análise, o spread entre os juros de captação da dívida brasileira e a taxa de juros livre de risco é aproximado pelo risco-país, medido pelo EMBI+ do Brasil. Há dois tipos de argumentos para se calcular a probabilidade de default, $\pi$, a partir da equação (5): de um lado, a teoria prevê que tal relação se manterá, pelo menos aproximadamente, sob hipóteses razoáveis; de outro lado, os dados necessários para se realizar o cálculo são facilmente obtidos. Não surpreendentemente, a maioria das aplicações empíricas do modelo BG adota esta relação sem hesitar. ${ }^{13}$

Procede-se, então, à estimação (implícita) de $\pi(R)$, isto é, de uma equação que ligue a probabilidade de default às reservas internacionais. A estimação é feita por meio de um modelo VAR, usando dados mensais para o período dentre março de 1999 e setembro de 2007 para as seguintes variáveis: o logaritmo natural de $\delta=\pi /(1-\pi)$, denominado PROB, o logaritmo da razão reservas/PIB (RES), o déficit primário do setor público consolidado como porcentagem do PIB (DEF) e o logaritmo do quociente entre a dívida externa bruta do setor público consolidado e o PIB (DEB). A inclusão das duas últimas variáveis busca capturar os efeitos de alguns indicadores de solvência fiscal sobre o risco-país. ${ }^{14}$ Além disso, a inclusão de DEB permite comparar a sensibilidade da probabilidade de crise em relação a dois empregos alternativos para as divisas: acumulação de reservas ou repagamento da dívida externa. Como variáveis exógenas, são incluídas duas dummies do tipo 0-1, uma para junho e outra para o período julho-outubro de 2002, a fim de captar o efeito das eleições presidenciais - que causaram fortes repercussões políticas e econômicas, bem como incertezas que levaram a uma fuga de capitais -, e o índice de volatilidade (VIX) do CBOE - Chicago Board Options Exchange, tanto contemporâneo quanto defasado, como proxy para a aversão global ao risco. Os dados para as variáveis domésticas foram obtidos no Banco Central do Brasil e, para as variáveis externas, vieram de: JP Morgan (índice EMBI), Federal Reserve (juros externos, medidos pelo retorno aos títulos de 10 anos do tesouro norte-americano, com maturidade constante), e CBOE (índice VIX).

O VAR é especificado com uma defasagem, conforme sugerido pelo Critério de Informação de Schwarz e pela aplicação do teste de autocorrelação residual de Breusch-Godfrey (que não detecta a presença de autocorrelação ao nível de significância de 5\%). Por meio da decomposição de Cholesky, com ordenação causal DEF - DEB - RES - PROB, obtém-se funções de

13 Ozyildirim e Yaman (2005) empregam uma metodologia ligeiramente diferente para calcular $\pi$, usando uma regressão GMM; Soto et al. (2004) empregam uma estimação logit para o Chile e uma regressão cross-section muito similar à de BG; Garcia e Soto (2006) também empregam um modelo logit e Blanco e Córdoba (1996) a mesma equação de BG.

14 A relevância de indicadores fiscais como determinantes de spreads soberanos é bem estabelecida na literatura; veja, por exemplo: Edwards (1984), Min (1998), Kamin e von Kleist (1999), Loureiro e Barbosa (2004), Manasse e Roubini (2005) e Rocha et al. (2006). Não consta nas referências. 
resposta a impulso que estão basicamente de acordo com as expectativas teóricas, como mostrado no Gráfico 3: a relação reservas/PIB tem um impacto negativo na probabilidade de default (Quadro A), enquanto que o déficit primário e a dívida externa têm impacto positivo - ainda que o efeito de DEB seja apenas marginalmente significativo (Quadros B e C). As linhas pontilhadas no Gráfico 3 são intervalos de confiança a 90\% e 95\% de significância, calculados por meio do método de bootstrap sugerido por Hall (1992).

\section{Gráfico 3 - Funções de resposta a impulso do VAR}

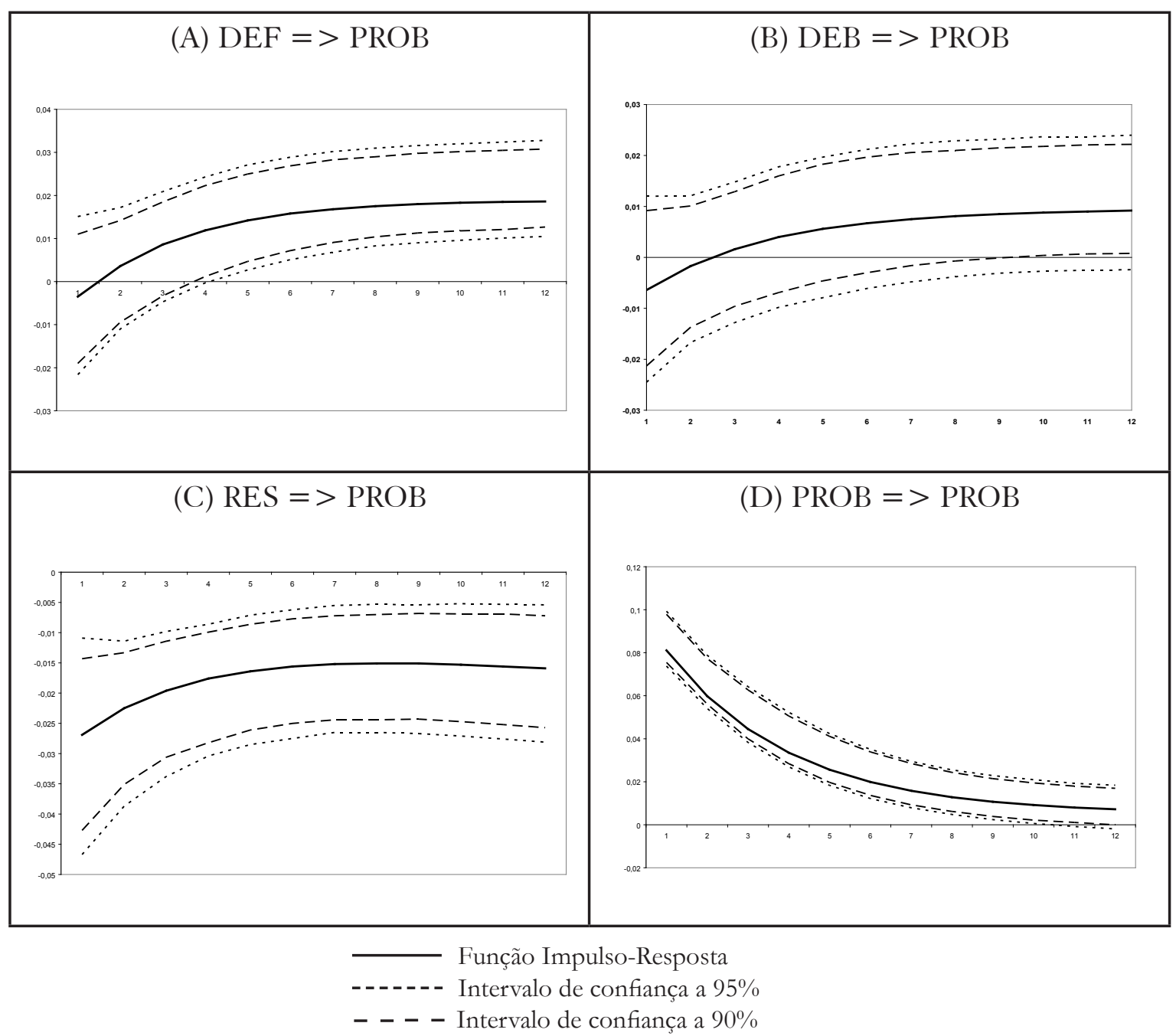

Cabe ressaltar que os resultados da estimação do VAR devem ser encarados com cautela, dado o tamanho reduzido da amostra disponível (103 observações) e a notória falta de parcimônia desse método, que requer a estimação de grande número de parâmetros. Entretanto, não parece haver solução fácil para esse problema, pois a mudança no regime de política macroeconômica no Brasil, ocorrida em 1999, com a adoção da política de metas de inflação sob taxa 
de câmbio flutuante, significa que os dados anteriores a 1999 são pouco informativos acerca da dinâmica das variáveis macroeconômicas no período mais recente.

A partir das funções de resposta a impulso, pode-se calcular a elasticidade (constante) de $\delta$ com respeito a $R$ para diferentes horizontes temporais. Na aplicação do modelo ao cálculo das reservas ótimas para o Brasil, o valor de $\varepsilon_{\delta, R}$, que entra na expressão (4”) é dado pela estimativa dessa elasticidade após um ano (12 períodos), igual a -0,3751. A equação de PROB no VAR "estrutural" identificado acima define, implicitamente, a função $\pi(R)$.

É interessante observar que a probabilidade de default parece mais sensível à acumulação de reservas do que ao repagamento da dívida pública externa: de um lado, a resposta de $\delta$ a choques em $R$ apresenta maior significância estatística do que a resposta de $\delta$ a choques em $D E B$; de outro lado, a elasticidade estimada de $\delta$ em relação a $R(-0,3751)$ é maior, em módulo, do que a elasticidade de $\delta$ em relação a $D E B(0,2922)$. Esse resultado é de suma importância, pois implica que, se o objetivo é reduzir o risco de default e sua percepção por parte dos agentes, pode ser mais interessante aplicar um dólar adicional em reservas internacionais do que no repagamento da dívida pública externa; caso esse resultado não se verificasse, a opção de repagar a dívida externa dominaria a alternativa de acumular reservas.

\subsection{Estimação de $r(\pi(R))$}

O custo de oportunidade de manter reservas internacionais, $r$, pode ser definido alternativamente como: (i) a diferença entre a produtividade marginal do capital da economia e o retorno sobre as reservas, e (ii) o spread entre a taxa de juros sobre a dívida externa e sobre as reservas. A definição (i), adotada no estudo clássico de BG, é julgada mais adequada do ponto de vista teórico por vários autores; ${ }^{15}$ entretanto, dadas as dificuldades de se obter estimativas confiáveis para o retorno do capital, a maior parte das aplicações do modelo de BG acaba utilizando a definição (ii). ${ }^{16}$ A seguir, apresentam-se estimativas desse custo de oportunidade sob ambas as definições. Vale destacar que a definição (i) parece compatível com a hipótese de exogeneidade do custo de oportunidade em relação ao nível das reservas - pois o retorno ao capital depende de variáveis estruturais da economia, como a oferta relativa de capital e trabalho, de aspectos institucionais, da produtividade da mão-de-obra, entre outros, o que claramente está muito pouco relacionado ao nível de reservas internacionais -, ao passo que, sob a definição (ii), o custo de oportunidade é claramente endógeno, tendo em vista que o spread sobre a dívida externa depende da probabilidade de default - que, por sua vez, é função do nível de reservas. Logo, somente sob a definição (ii) faz sentido falar de uma função $r(\pi(R))$.

15 Segundo Edwards (1985, p. 288), por exemplo: "The correct measure of this opportunity cost will be a net cost, given by the difference between the domestic marginal product of capital - which will capture the gross forgone income from holding resources in the form of international reserves and the return obtained from holding the reserves." Ver também a discussão em Ben-Bassat e Gottlieb (1992a).

16 Ver, por exemplo, Angaríta (2006), Ozyildirim e Yaman (2005), GIE (2004), Vimolchalao (2003), Blanco e Córdoba (1996) e Oliveros e Varela (1994). Cabe ressaltar, porém, que tais estudos ignoram a endogeneidade do custo de oportunidade em relação ao nível de reservas, gerando viés potencialmente significativo no cálculo das reservas ótimas. Ver, a esse respeito, a discussão em Cavalcanti e Vonbun (2007). 
O cálculo do custo de oportunidade de manter reservas segundo a definição (i) requer uma estimativa do retorno sobre o capital na economia brasileira. Este é calculado como a razão média entre o lucro bruto das empresas e o estoque líquido de capital da economia entre 2001 e 2006, corrigido para a desvalorização esperada média do câmbio, o que gera uma estimativa de $8,5 \%$ ao ano. O custo de oportunidade é, então, calculado como a diferença entre esse retorno e a taxa de juros dos títulos de 10 anos do Tesouro norte-americano - usado como proxy para o retorno sobre as reservas. As fontes dos dados para o cálculo do retorno sobre o capital são as Contas Nacionais do IBGE (lucros), o IPEADATA (estoque de capital) e o Banco Central do Brasil (desvalorização cambial esperada).

Sob a definição (ii), o custo de oportunidade das reservas é simplesmente dado pelo spread entre a taxa média de juros sobre a dívida externa brasileira e a taxa de juros dos títulos de dez anos do Tesouro norte-americano. Nesse caso, como argumentado acima, o custo de oportunidade é endógeno em relação às reservas; de fato, a partir da relação (5), pode-se escrever o custo de oportunidade como:

$$
r=i_{D}-i_{i}=\frac{\pi}{1-\pi}\left(1+i_{i}\right)
$$

deixando clara sua dependência em relação à probabilidade de default - e, conseqüentemente, em relação ao nível de reservas. A partir de (6), é fácil verificar que $\varepsilon_{r, \pi}=(1-\pi)^{-1}$, o que pode ser usado em (4”).

\subsection{Cenários alternativos para $C(R)$}

A estimação da função $C(R)$ é tarefa que vai além do escopo deste artigo. Nas simulações da próxima seção, opta-se simplesmente por trabalhar com cenários alternativos, dentro de intervalos julgados "razoáveis" (à luz da literatura sobre o tema), para os custos de uma crise de default, $C$, e para a sensibilidade desses custos ao nível de reservas internacionais.

No que se refere ao custo de uma crise de default, os cenários baseiam-se nas estimativas de Barro (2001), Hutchinson e Noy (2005) e De Gregorio e Lee (2003). De acordo com Barro (2001), o custo de uma crise cambial "típica" é de 1,3\% do PIB por ano, durante cinco anos, levando a um total não descontado de cerca de 6,7\% do PIB; se combinada a uma crise bancária, a crise implicaria um custo esperado total de 10\% do PIB. Para a crise asiática de 1997-98, contudo, os custos estimados por Barro sobem para 3\% do PIB ao ano, totalizando 15\% após cinco anos. A análise de Hutchinson e Noy (2005), por sua vez, sugere que o custo de uma crise cambial deve girar em torno de $5 \%$ a $8 \%$ do PIB, enquanto que o custo de uma crise bancária deve atingir cerca de $8 \%$ a $10 \%$ do PIB, ao longo de $2-4$ anos; logo, o custo esperado de uma crise cambial e bancária seria de $13 \%$ a $18 \%$ do PIB. Por fim, De Gregório e Lee (2003) obtêm estimativas para os custos de uma crise de balanço de pagamentos variando entre 5,8\% e 8,8\% do PIB, ao longo de 3-5 anos. Com base nessas estimativas, o cenário mais provável para os custos de uma crise parece situar-se entre 5\% e 10\% do PIB; entretanto, nas simulações a seguir, 
opta-se por trabalhar com um intervalo mais amplo para os custos de default, variando entre $2,5 \%$ e $15 \%$ do PIB.

No que tange à sensibilidade do custo de default ao nível de reservas internacionais, os cenários baseiam-se nos resultados de De Gregorio e Lee (2003), que encontram efeitos estatisticamente significativos das razões reservas/dívida externa de curto prazo e reservas/M2 sobre os custos de uma crise de balanço de pagamentos. A partir dos efeitos estimados por esses autores, é possível inferir uma elasticidade média do custo de default em relação às reservas, cuja estimativa varia entre $-0,04 \mathrm{e}-0,50 .^{17}$ Conseqüentemente, nas simulações a seguir, trabalha-se com cenários alternativos para a elasticidade de $C$ com respeito a $R$ variando entre 0 e $-0,5$. Os cenários com elasticidade zero correspondem, evidentemente, aos Casos I e II descritos na seção anterior, caracterizados por custos de default exógenos.

Os cenários acima são implementados, por conveniência, por meio de uma forma funcional para $C(R)$ caracterizada por elasticidade constante, dependendo de apenas dois parâmetros, $\beta_{0}$ e $\beta_{1}$ :

$$
C=\beta_{0}\left(\frac{R}{Y}\right)^{-\beta_{1}}
$$

onde $Y$ é o PIB do país. O valor de $\beta_{1}$ corresponde, evidentemente, à elasticidade de $C$ com respeito a $R$ e varia, nas simulações, entre 0 e $-0,5$. Para um dado valor de $\beta_{1}$, o custo de uma crise de default depende da razão $R / Y$ e do valor de $\beta_{0}$. Sob a hipótese de que os cenários para o custo de default variando entre $2,5 \%$ e $15 \%$ do PIB sejam válidos para a razão $R / Y$ média observada no Brasil durante o período 1999:1-2005:12 (dada por 0,07), o valor de $\beta_{0}$ é determinado, para cada valor de $\beta_{1}$ e cada valor do custo "médio" de default ( $\bar{C}$ a partir da seguinte expressão:

$$
\beta_{0}=\frac{\bar{C}}{(0,07)^{-\beta_{1}}}
$$

17 No estudo de De Gregório e Lee (2003), os efeitos estimados das razões reservas/dívida externa de curto prazo e reservas/M2 sobre o custo de uma crise são, respectivamente, -0,0025 e -0,146, enquanto que o custo médio de uma crise (em termos de perda de produto) varia entre 0,058 e 0,088. A fim de calcular as elasticidades de interesse a partir dessas estimativas, recorreu-se a dados do International Financial Statistics (IFS), do FMI, e a dados do BID. A partir de dados do IFS, a razão reservas/M2 média na amostra de De Gregorio e Lee é de aproximadamente 0,3 , levando a uma estimativa da elasticidade média na amostra de $-0,498$. Não foi possível obter dados referentes à razão reservas/dívida externa de curto prazo para todo o período amostral (1975-1998) usado por De Gregorio e Lee; entretanto, dados do BIS para 1990 indicam uma razão média de 0,84 para um conjunto amplo de países analisados por tais autores. Com base nessa estimativa, a elasticidade média do custo de uma crise em relação às reservas seria de aproximadamente $-0,04$. Vale ressaltar que, para qualquer valor da razão reservas/dívida externa de curto prazo dentro de um intervalo "razoável”, a elasticidade estimada é sempre relativamente baixa; de fato, para valores da razão reservas/dívida externa de curto prazo no intervalo entre 0,5 e 2 , a elasticidade do custo de uma crise em relação às reservas varia entre $-0,02 \mathrm{e}-0,09$. 


\section{CÁlCUlo dAS RESERVAS Ótimas PARA O BRASIL}

\subsection{Caso I: Custo de default exógeno/custo de oportunidade exógeno}

Para o Caso I (custos de default e de oportunidade exógenos), o Gráfico 4 apresenta os níveis ótimos de reservas calculados para cada mês no período 1999:3-2007:9, sob vários cenários para os custos de uma crise de default, e os compara com os níveis observados de reservas no Brasil. Nota-se que as reservas observadas, que se encontravam abaixo do nível ótimo até o início de 2003 sob a maioria dos cenários considerados, gradualmente alcançaram e ultrapassaram esse nível, tornando-se "excessivas" a partir de 2004 ou 2005. Assim, pela especificação original de BG, desde o final de 2005 já não é mais possível justificar o montante de liquidez internacional mantido pelo Banco Central do Brasil, e o processo recente de forte acumulação de reservas seria equivocado.

A trajetória dos níveis ótimos de reservas calculados pelo modelo é explicada, em grande medida, pela evolução da probabilidade de crise, captada pela variação do risco-país no período; em particular, a tendência de queda dessa probabilidade (interrompida momentaneamente em 2002, devido às incertezas geradas pelas eleições presidenciais daquele ano) implicou menor necessidade de um "seguro" contra crises - e, portanto, menores níveis de reservas ótimas.

A Tabela 2 apresenta, para cada ano do período analisado, estimativas do "desperdício" de recursos associado à manutenção de reservas internacionais em níveis diferentes do ótimo - que corresponde, simplesmente, ao custo de oportunidade do "excesso" de reservas em relação ao ótimo. Cabe notar que, nos anos em que as reservas estiveram abaixo do ótimo, houve ganho líquido para o País segundo essa definição. De acordo com a tabela, o desperdício de recursos teria aumentado muito nos últimos anos, atingindo valores substanciais em 2007. Sob o cenário julgado mais provável para o custo de default - equivalente a 7,5\% do PIB -, o valor ótimo das reservas para o mês de setembro de 2007 seria de US\$ 49,6 bilhões, contra um valor observado de quase US\$ 163 bilhões, gerando um excesso de US\$113,3 bilhões e um desperdício de recursos, em termos anualizados, de US $\$ 4,5$ bilhões. Levando em consideração os cenários alternativos para os custos de default, o excesso de reservas observado em setembro de 2007 poderia levar a um desperdício de recursos entre US\$3,4 e US\$5,5 bilhões/ano. 


\section{Gráfico 4 - Reservas ótimas sob diferentes cenários para o custo de default - Caso I}

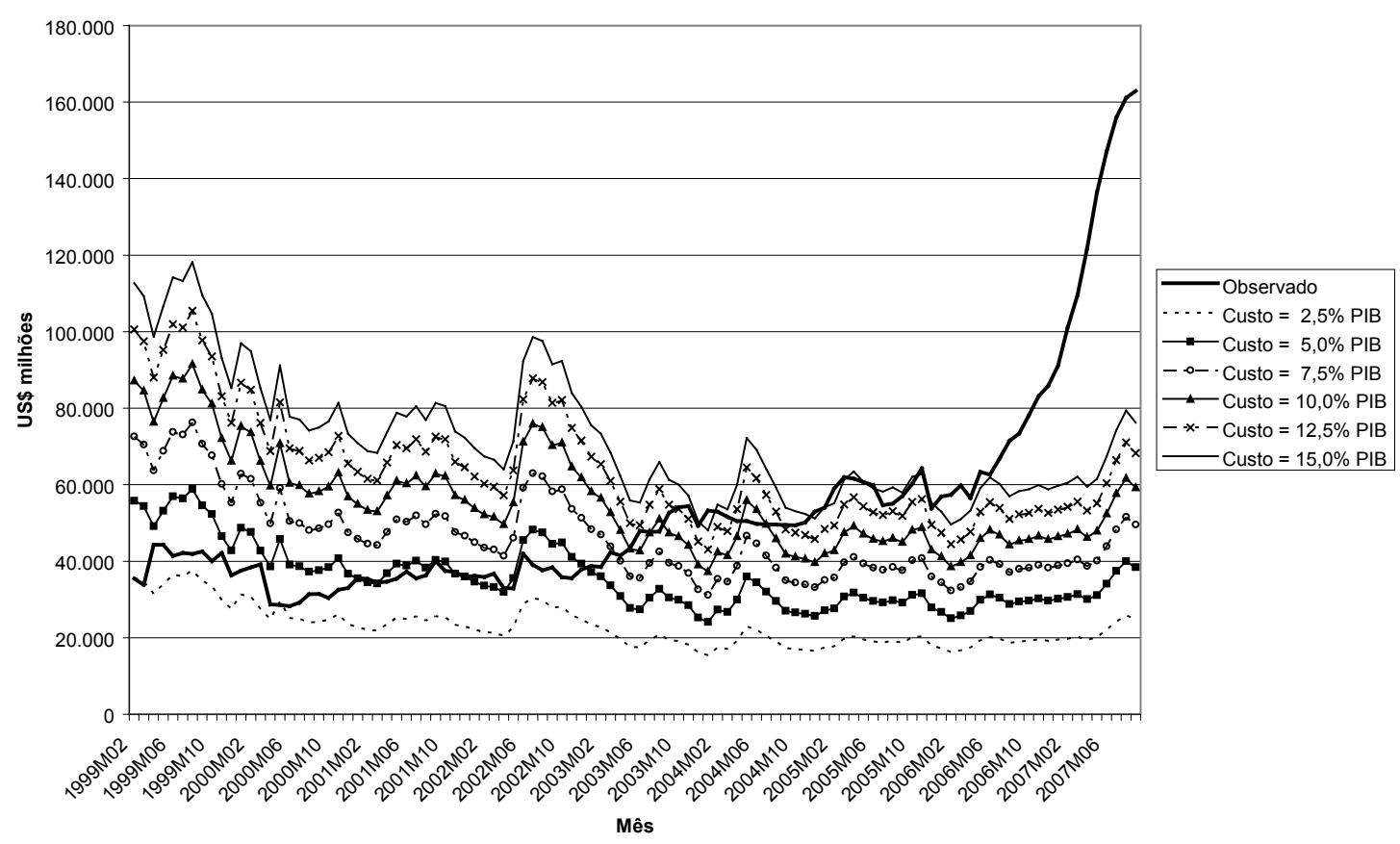

Tabela 2 - Desperdício/economia (+/-) anualizado(a) de se manter reservas fora do ótimo, em US $\$$ milhões, por cenário de custo de crise (\% do PIB)

\begin{tabular}{lrrrrrr}
\hline Cenário $=>$ & $2,50 \%$ & $5 \%$ & $7,50 \%$ & $10 \%$ & $12,50 \%$ & \multicolumn{1}{c}{$15 \%$} \\
\hline 2000 & 151,14 & $(205,45)$ & $(497,27)$ & $(753,51)$ & $(986,13)$ & $(1.201,49)$ \\
2001 & 428,91 & $(42,82)$ & $(429,65)$ & $(769,69)$ & $(1.078,61)$ & $(1.364,74)$ \\
2002 & 435,89 & $(143,94)$ & $(621,33)$ & $(1.041,86)$ & $(1.424,41)$ & $(1.779,09)$ \\
2003 & $1.198,90$ & 695,65 & 282,29 & $(81,39)$ & $(411,96)$ & $(718,27)$ \\
2004 & $1.373,04$ & 938,33 & 582,14 & 269,17 & $(15,08)$ & $(278,30)$ \\
2005 & $1.657,73$ & $1.212,23$ & 847,67 & 527,55 & 236,94 & $(32,09)$ \\
2006 & $1.838,03$ & $1.463,15$ & $1.156,88$ & 888,19 & 644,42 & 418,83 \\
$2007^{*}$ & $4.116,98$ & $3.670,74$ & $3.306,15$ & $2.986,28$ & $2.696,05$ & $2.427,47$ \\
Set/2007 & $5.496,90$ & $4.954,86$ & $4.511,80$ & $4.122,97$ & $3.770,13$ & $3.443,57$ \\
\hline
\end{tabular}

* Média mensal anualizada até setembro.

* Custo anualizado de se manter as reservas no nível observado no mês, coeteris paribus.

\subsection{Caso II: Custo de default exógeno/custo de oportunidade endógeno}

Os níveis ótimos de reservas para o Caso II, retratados no Gráfico 5, apresentam evolução muito diferente da observada no Caso I. Até o final de 2002, as reservas ótimas se mostraram 
estáveis ou levemente declinantes, e a partir de então começaram a subir; sob a maioria dos cenários de custo de default considerados, porém, as reservas ótimas estiveram quase sempre abaixo das reservas observadas, em claro contraste com o caso anterior.

A diferença entre os dois casos é explicada, basicamente, pela maior sensibilidade do nível ótimo de reservas em relação ao custo de oportunidade quando este último é endógeno - de modo que, diante da redução do spread sobre a dívida externa a partir de 2003 - e, portanto, do custo de reter reservas -, as reservas ótimas tenderam a se elevar.

É interessante notar que, para custos de default elevados, as reservas ótimas seguiram, de forma aproximada, a evolução do nível observado de reservas durante grande parte do período. Em particular, para custos de default entre 7,5\% e 15\% do PIB, o nível observado de reservas se mostrou razoavelmente "adequado" entre 1999 e 2001, e permaneceu assim até o final de 2006 para os cenários mais "pessimistas”. A partir de 2007, contudo, a forte acumulação de reservas pelo Banco Central deixou de ser justificada mesmo sob esses cenários. O excesso de reservas para o último dado disponível, setembro de 2007, oscilava entre US\$ 63 bilhões e US\$ 147 bilhões, de acordo com o cenário para o custo de crise.

\section{Gráfico 5 - Reservas ótimas sob diferentes cenários para o custo de default - Caso II}

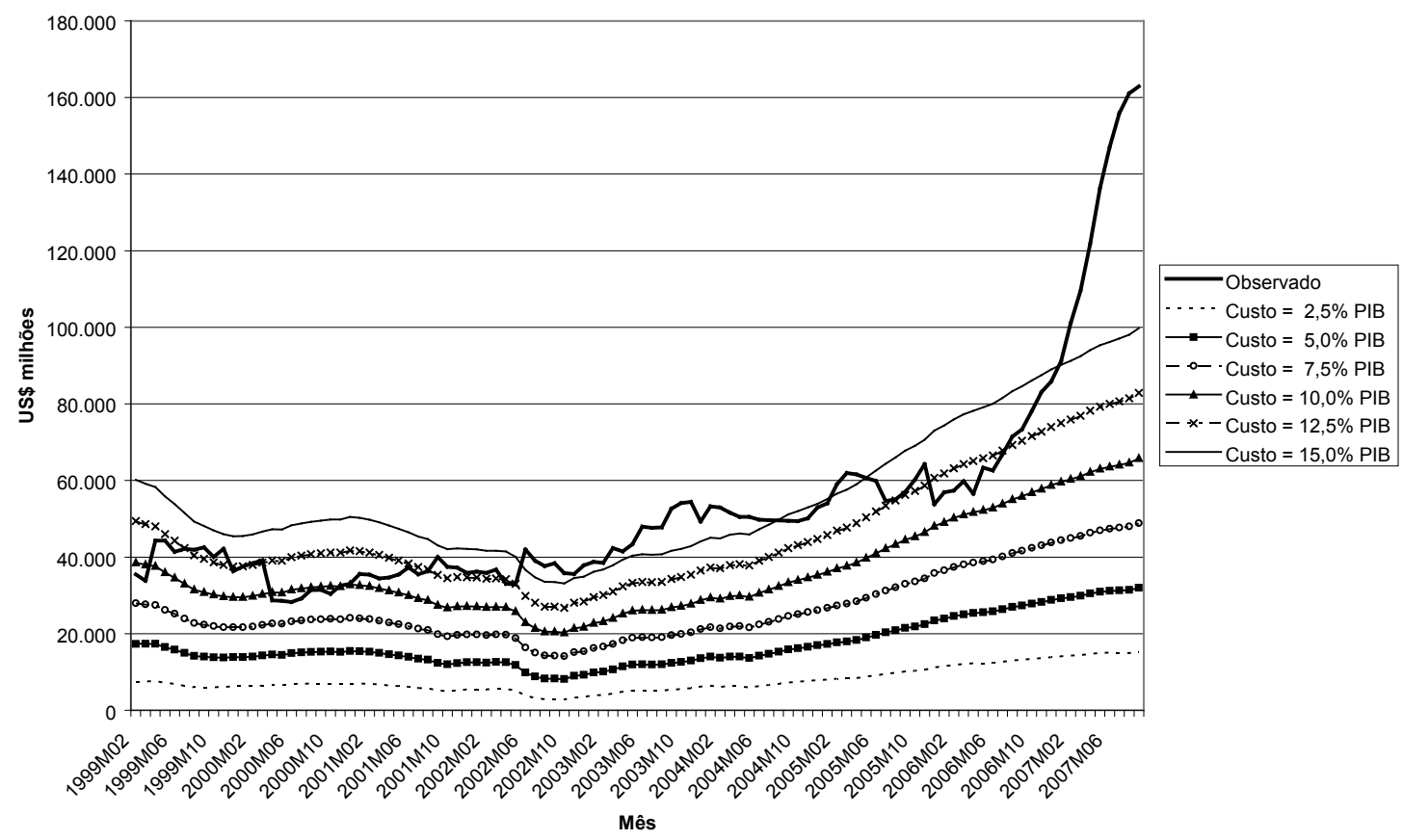

A Tabela 3 mostra as perdas/ganhos médios associados à manutenção das reservas fora do ótimo, por ano e por cenário. Nota-se que, após caírem entre 2002 e 2006, os custos de manutenção de volumes excessivos de reservas voltaram a subir em 2007 sob todos os cenários, atingindo valores entre US $\$ 505$ milhões e US $\$ 1,8$ bilhões, em termos anualizados, em setembro 
de 2007. Entretanto, as perdas revelam-se, aqui, substancialmente inferiores às perdas observadas no Caso I, devido à subestimação do spread sobre a dívida externa - e, conseqüentemente, do custo de oportunidade das reservas - pelo modelo.

Tabela 3 - Desperdício/economia (+/-) anualizado(a) de se manter reservas fora do ótimo, em US \$ milhões, por cenário de custo de crise (\% do PIB)

\begin{tabular}{lrrrrrr}
\hline Cenário $=>$ & $2,50 \%$ & \multicolumn{1}{c}{$5 \%$} & $7,50 \%$ & $10 \%$ & $12,50 \%$ & $15 \%$ \\
\hline 2000 & $1.024,90$ & 583,97 & 273,78 & 25,89 & $(184,23)$ & $(368,52)$ \\
2001 & $1.575,49$ & 987,51 & 575,60 & 247,15 & $(30,82)$ & $(274,36)$ \\
2002 & $2.894,94$ & $1.985,85$ & $1.352,54$ & 850,06 & 426,33 & 56,08 \\
2003 & $2.103,61$ & $1.488,20$ & $1.058,02$ & 715,49 & 425,87 & 172,30 \\
2004 & $1.433,70$ & 994,91 & 686,33 & 439,76 & 230,80 & 47,53 \\
2005 & $1.143,69$ & 763,34 & 494,75 & 279,69 & 97,19 & $(63,01)$ \\
2006 & 721,61 & 460,56 & 275,40 & 126,80 & 0,53 & $(110,42)$ \\
2007 & $1.263,20$ & 949,29 & 726,70 & 548,09 & 396,32 & 262,98 \\
Set/2007* & $1.785,89$ & $1.383,48$ & $1.098,44$ & 869,85 & 675,67 & 505,11 \\
\hline
\end{tabular}

* Média mensal anualizada até setembro.

* Custo anualizado de se manter as reservas no nível observado no mês, coeteris paribus.

\subsection{Caso III: Custo de default endógeno/custo de oportunidade exógeno}

O Gráfico 6 apresenta os níveis ótimos de reservas calculados para o Caso III (custo de default endógeno e custo de oportunidade exógeno), sob a hipótese de um custo de crise médio de $7,5 \%$ do PIB e cenários para a elasticidade desse custo em relação às reservas $\left(\varepsilon_{C, R}\right)$ variando entre $0 \mathrm{e}-0,5$. Evidentemente, quando $\varepsilon_{C, R}=0$, o custo de crise torna-se exógeno em relação às reservas, e o modelo se reduz ao modelo do Caso I - de modo que a trajetória do nível ótimo de reservas correspondente a uma elasticidade nula é idêntica à trajetória vista anteriormente para o Caso I, quando o custo de default era 7,5\% do PIB.

Nota-se que, em comparação com o Caso I, a endogeneidade do custo de default opera no sentido de aumentar o nível ótimo de reservas, conforme esperado - pois a posse de reservas gera, agora, um benefício adicional para o País em termos de redução do custo de uma crise, caso esta ocorra. Entretanto, esse efeito é relativamente fraco, mesmo para os cenários com $\varepsilon_{C, R}$ elevado, de modo que a avaliação da política de acumulação de reservas pelo Banco Central do Brasil permanece basicamente inalterada em relação ao Caso I. Em outras palavras, o modelo sugere que as reservas observadas, que se encontravam abaixo do nível ótimo no início da amostra, a partir de certo momento tornaram-se "excessivas", passando a gerar perdas líquidas para o País. Em particular, a partir de abril de 2006, nem mesmo a hipótese de uma elasticidade igual a $-0,5$ é capaz de justificar o montante de reservas mantido pela autoridade monetária. Em setembro de 2007, o "excesso" de reservas, de acordo com os cenários, variava entre US\$ 78,1 bilhões e US $\$ 113,3$ bilhões. Tomando como base esse mês, a perda social de se manter as 
reservas fora do ótimo variava entre US\$3,1 e US $\$$ 4,5 bilhões (Tabela 4), dependendo do valor de $\varepsilon_{C, R}$.

Gráfico 6 -Reservas ótimas sob custo de crise médio de 7,5\% do PIB e diferentes cenários para a elasticidade do custo de crise em relação às reservas - Caso III

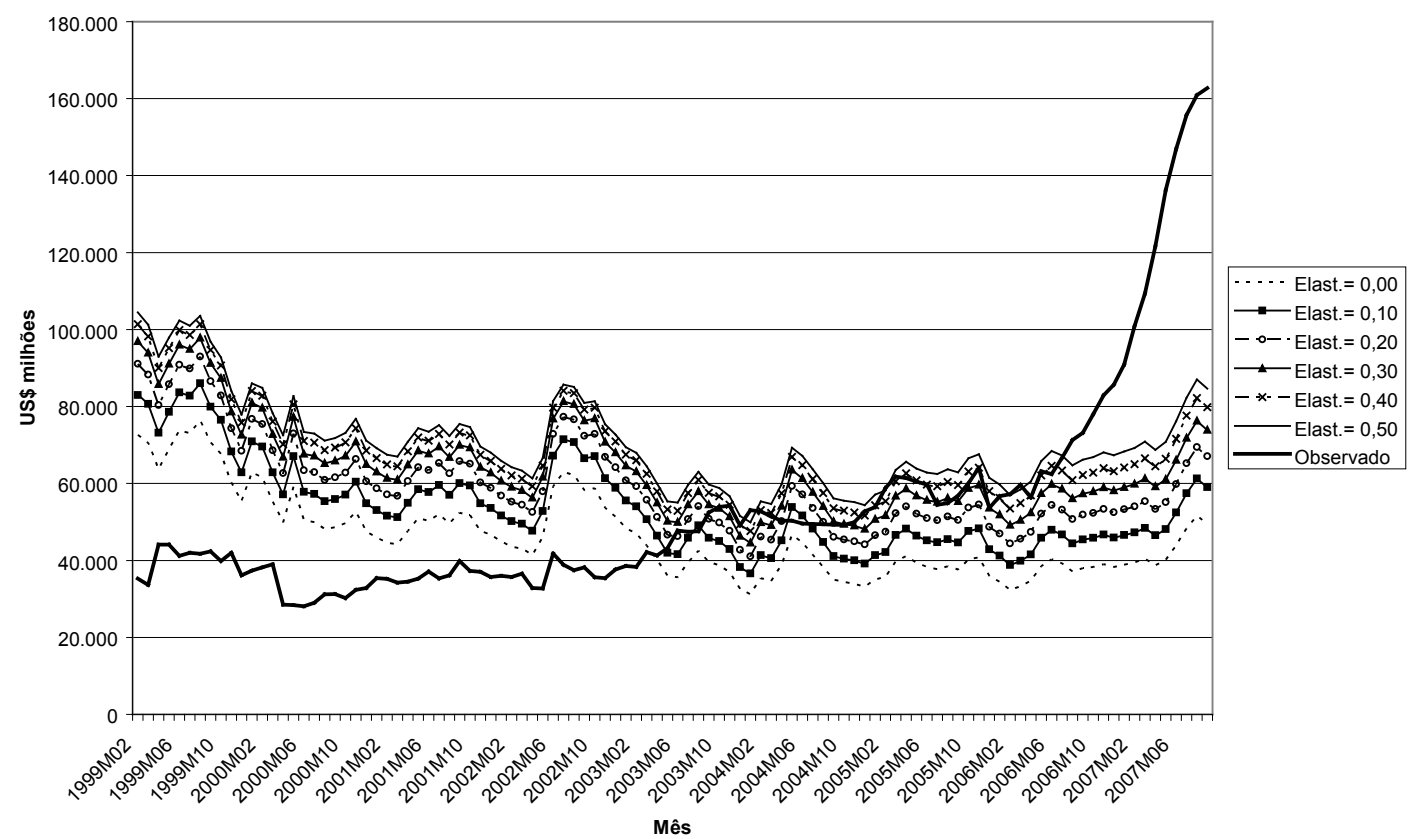

Tabela 4 - Desperdício/economia (+/-) anualizado de se manter reservas fora do ótimo, em US \$ milhões, por cenário de elasticidade-reservas do custo de crise (custo médio: $7,5 \%$ do PIB)

\begin{tabular}{lcrrrrr}
\hline Cenário => & 0 & \multicolumn{1}{c}{0,1} & \multicolumn{1}{c}{0,2} & \multicolumn{1}{c}{0,3} & \multicolumn{1}{c}{0,4} & \multicolumn{1}{c}{0,5} \\
\hline 2000 & $(497,27)$ & $(682,92)$ & $(824,35)$ & $(932,10)$ & $(1.013,94)$ & $(1.075,72)$ \\
2001 & $(429,65)$ & $(684,89)$ & $(879,70)$ & $(1.028,64)$ & $(1.142,31)$ & $(1.228,65)$ \\
2002 & $(621,33)$ & $(914,98)$ & $(1.127,46)$ & $(1.281,13)$ & $(1.391,34)$ & $(1.469,07)$ \\
2003 & 282,29 & $(3,03)$ & $(222,69)$ & $(392,40)$ & $(523,53)$ & $(624,61)$ \\
2004 & 582,14 & 317,59 & 105,29 & $(65,62)$ & $(203,45)$ & $(314,66)$ \\
2005 & 847,67 & 555,94 & 313,95 & 112,80 & $(54,67)$ & $(194,28)$ \\
2006 & $1.156,88$ & 889,41 & 658,94 & 460,40 & 289,33 & 141,81 \\
$2007^{\star}$ & $3.306,15$ & $2.988,86$ & $2.715,88$ & $2.481,05$ & $2.278,96$ & $2.104,89$ \\
Set/2007 & $4.511,80$ & $4.135,26$ & $3.814,68$ & $3.541,57$ & $3.308,73$ & $3.110,00$ \\
\hline
\end{tabular}

* Média mensal anualizada até setembro.

** Custo anualizado de se manter as reservas no nível observado no mês, coeteris paribus.

Os cálculos acima tomam por base o valor julgado mais provável para o custo médio de crise, da ordem de 7,5\% do PIB. É interessante, porém, analisar também os resultados sob um custo de 
crise médio de 15\% do PIB, que constitui o cenário mais favorável à acumulação de reservas - e, portanto, à política recente de reservas do Banco Central. Esses resultados são mostrados no Gráfico 7. Nota-se que, nesse caso, as reservas observadas estiveram abaixo do nível ótimo até o final de 2006 ou início de 2007 (dependendo da hipótese acerca de $\varepsilon_{C, R}$ ), indicando que o processo de acumulação de reservas verificado ao longo de 2006 teria sido justificável, à luz do modelo. Entretanto, mesmo nesse caso, a partir de fevereiro de 2007, as reservas observadas já superavam o nível ótimo sob todos os cenários para $\varepsilon_{C, R}$ e, em setembro, o excesso de reservas estimado variava entre US $\$ 45,3$ bilhões e US $\$ 86,5$ bilhões.

Gráfico 7 - Reservas ótimas sob custo de crise médio de 15\% do PIB e diferentes cenários para a elasticidade do custo de crise em relação às reservas - Caso III

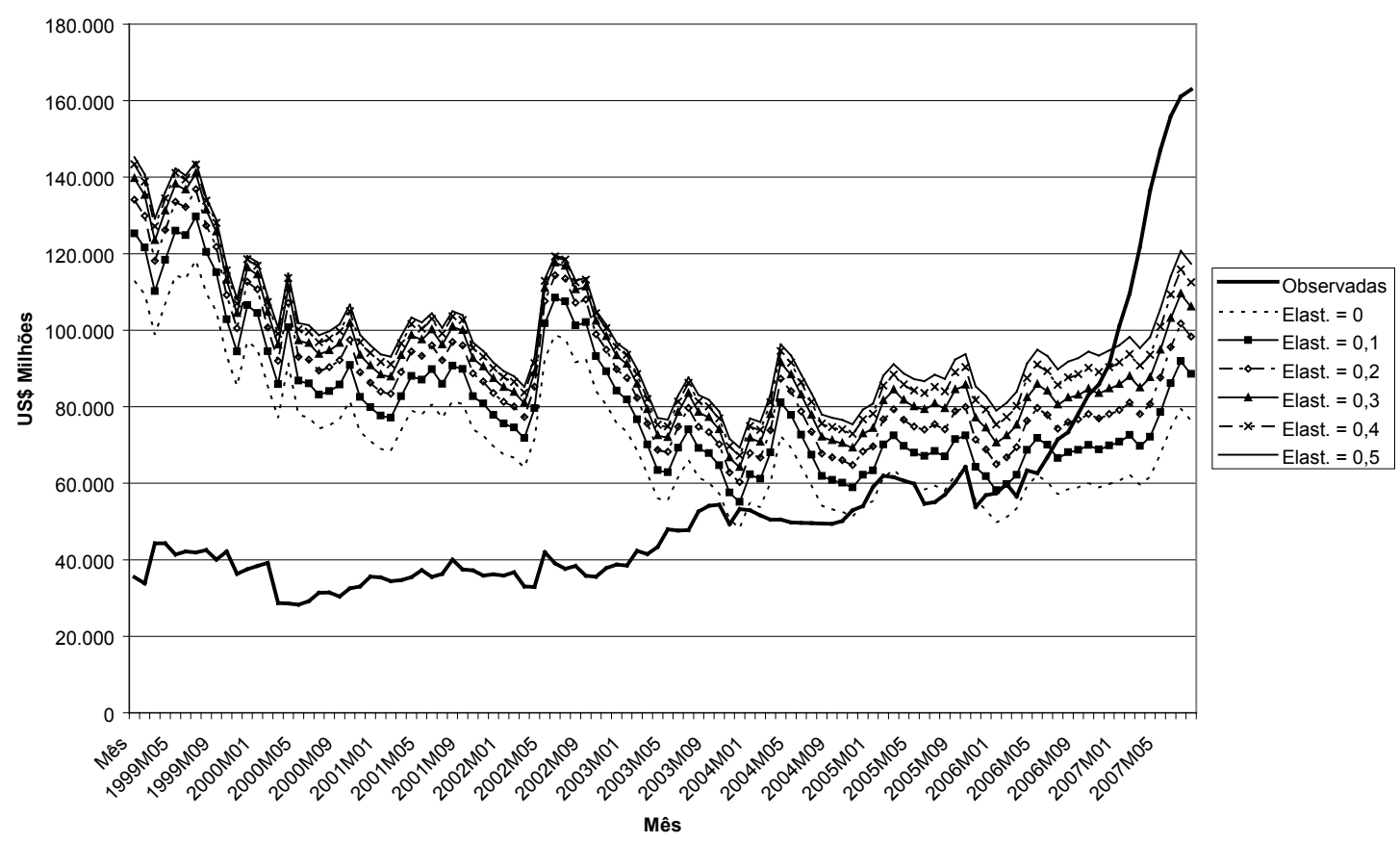

\subsection{Caso IV: Custo de default endógeno/custo de oportunidade endógeno}

As reservas ótimas para o Caso IV são apresentadas no Gráfico 8. Assim como na subseção anterior, trabalha-se com a hipótese de um custo de crise médio de 7,5\% do PIB e cenários para $\varepsilon_{C, R}$ variando entre 0 e $-0,5$.

Os níveis de reservas ótimas correspondem a deslocamentos para cima das trajetórias verificadas no Caso II, dado o benefício adicional proporcionado pelas reservas em termos de mitigação de crises. De modo geral, o modelo explica razoavelmente bem o comportamento das reservas observadas no período sob análise - sugerindo que o Banco Central do Brasil teria adotado uma política de reservas próxima da ótima durante grande parte do período. Ainda 
assim, a partir de fevereiro de 2007, o modelo já era incapaz de justificar o montante de reservas acumulado pelo Banco Central, mesmo sob valores relativamente elevados de $\varepsilon_{C, R}$. O excesso de liquidez internacional em relação ao ótimo, em setembro de 2007, variava de US\$ 57,2 bilhões a US $\$ 114,0$ bilhões, de acordo com a elasticidade assumida.

Gráfico 8 - Reservas ótimas sob custo de crise médio de 7,5\% do PIB e diferentes cenários para a elasticidade do custo de crise em relação às reservas - Caso IV

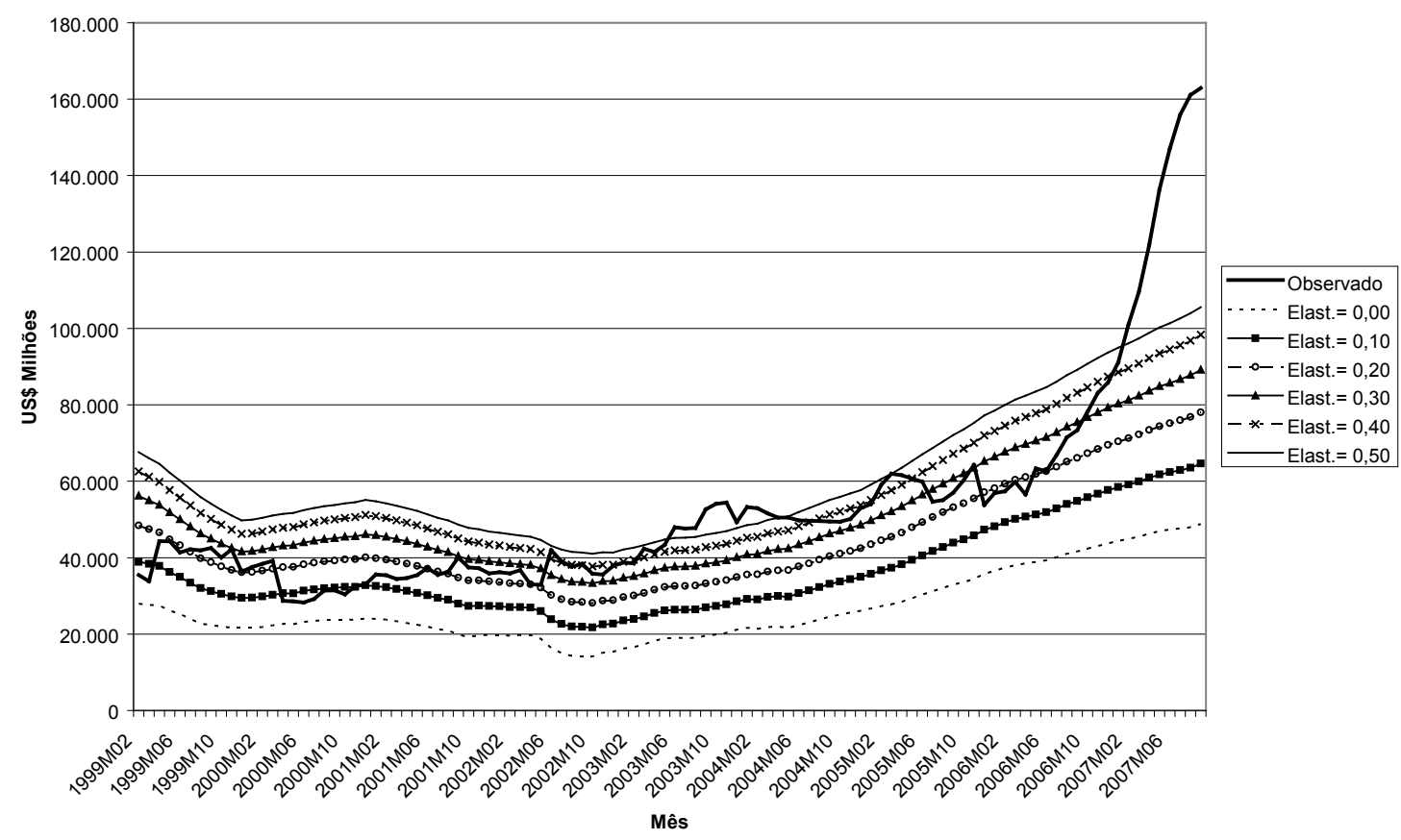

Assim como no Caso II, também aqui os custos de oportunidade de reter reservas calculados pelo modelo parecem subestimados, de modo que, apesar de excedentes de reservas bastante elevados, as perdas sociais revelam-se limitadas. A Tabela 5 ilustra as perdas associadas ao desvio das reservas observadas em relação ao ótimo; em termos anualizados, os prejuízos líquidos de se manter reservas no patamar de setembro de 2007 variavam entre US\$ 451,3 milhões e US\$1,1 bilhão. 
Tabela 5 - Desperdício/economia (+/-) anualizado de se manter reservas fora do ótimo, em US \$ milhões, por cenário de elasticidades-reservas do custo de crise (custo médio: $7,5 \%$ do PIB)

\begin{tabular}{lrrrrrr}
\hline Cenário $=>$ & 0,00 & 0,10 & 0,20 & 0,30 & \multicolumn{1}{c}{0,40} & \multicolumn{1}{c}{0,50} \\
\hline 2000 & 273,78 & 29,79 & $(147,39)$ & $(279,50)$ & $(379,68)$ & $(456,57)$ \\
2001 & 575,60 & 242,00 & 2,70 & $(174,59)$ & $(308,54)$ & $(411,11)$ \\
2002 & $1.352,54$ & 785,60 & 394,61 & 109,81 & $(103,50)$ & $(266,11)$ \\
2003 & $1.058,02$ & 702,70 & 450,17 & 263,93 & 123,62 & 16,39 \\
2004 & 686,33 & 444,26 & 268,92 & 138,47 & 39,74 & $(35,90)$ \\
2005 & 494,75 & 289,67 & 139,79 & 27,80 & $(57,16)$ & $(122,31)$ \\
2006 & 275,40 & 137,47 & 35,76 & $(40,59)$ & $(98,67)$ & $(143,28)$ \\
$2007^{\star}$ & 726,70 & 560,66 & 438,29 & 346,44 & 276,59 & 222,94 \\
Set/2007 & $1.098,44$ & 884,68 & 727,47 & 609,62 & 520,05 & 451,30 \\
\hline
\end{tabular}

* Média mensal anualizada até setembro.

* Custo anualizado de se manter as reservas no nível observado no mês, coeteris paribus.

O Gráfico 9 apresenta os resultados sob a hipótese de custo médio de crise da ordem de 15\% do PIB. Esse é o cenário mais favorável possível à política de acumulação de reservas verificada recentemente no País, pois incorpora todos os benefícios que, no contexto do modelo teórico analisado, podem ser gerados por maiores volumes de reservas - redução da probabilidade de crise, mitigação dos efeitos da crise e redução do custo de oportunidade das reservas - e pressupõe que os custos potenciais de uma crise sejam efetivamente elevados. Nesse caso, observa-se que, sob praticamente todos os cenários para $\varepsilon_{C, R}$, as reservas ótimas sempre estiveram acima das reservas observadas até dezembro de 2006 - o que aponta para a adequação da política de acumulação de reservas verificada entre 2006 e 2007. Além disso, para valores elevados de $\varepsilon_{C, R}$, ainda seria possível justificar patamares de reservas semelhantes ao mantido pela autoridade monetária no final do período analisado (setembro de 2007). 
Gráfico 9 - Reservas ótimas sob custo de crise médio de $15 \%$ do PIB e diferentes cenários para a elasticidade do custo de crise em relação às reservas - Caso IV

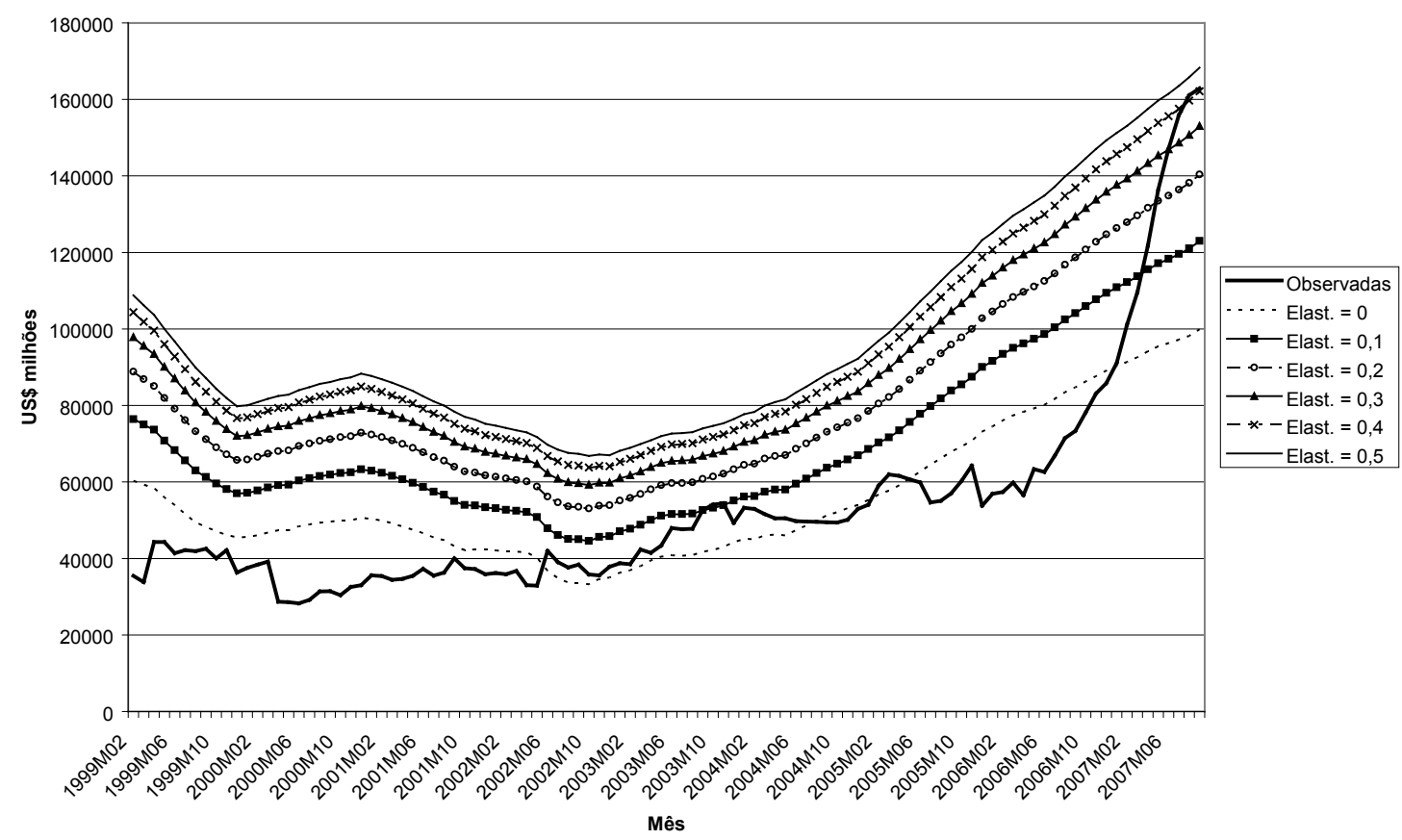

\subsection{Discussão dos resultados}

A Tabela 6 resume os valores ótimos das reservas obtidos sob cada um dos casos considerados, para cenários de custo de crise - médio ou absoluto, conforme o caso - de 7,5\% do PIB e para elasticidades desse custo em relação às reservas de - 0,3 , quando aplicável. Até 2006, são reportadas as médias anuais e, a partir de 2007, os valores mensais calculados.

Claramente, as estimativas do nível ótimo de reservas, bem como as perdas econômicas associadas aos desvios das reservas observadas em relação a esse nível, variam de forma substancial entre os modelos considerados e seus respectivos cenários. Em conseqüência disso, a análise da adequação (ou não) dos níveis de reservas observados no Brasil entre 1999 e 2007 - em particular, a avaliação do processo de forte acumulação de reservas observado entre 2006 e 2007 - permite múltiplas conclusões. De acordo com os modelos com custo de oportunidade exógeno (Casos I e III), as reservas internacionais do País estiveram abaixo do nível ótimo durante os primeiros anos do período analisado, mas se tornaram excessivas a partir de algum momento situado, dependendo do cenário considerado, entre 2004 e 2006; a recente acumulação de reservas pelo Banco Central do Brasil seria, portanto, injustificada e estaria gerando perdas significativas para o País. Por sua vez, os quadros traçados pelos modelos com custo de oportunidade endógeno (Casos II e IV) dependem do cenário adotado para a magnitude dos custos de uma crise de default e para a sensibilidade desses custos ao nível de reservas. Sob custos de default 
relativamente baixos e pouco sensíveis às reservas, o nível observado de reservas esteve acima das reservas ótimas durante a maior parte do período em questão, e tal excesso de reservas teria se agravado no período recente - gerando perdas crescentes para o País. Entretanto, à medida que se consideram cenários com custos de default mais elevados ou sensíveis ao nível de reservas do País, as estimativas do nível ótimo de reservas aumentam ao longo de todo o período, o que permite justificar, pelo menos parcialmente, o crescimento das reservas brasileiras a partir de 2006.

Tabela 6 - Reservas ótimas para um custo de crise de 7,5\% do PIB e elasticidade de 0,3 c(quando aplicável) em US\$ milhões

\begin{tabular}{lllllc}
\hline Ano/mês & Caso I & Caso II & Caso III & Caso IV & Observadas \\
\hline 2000 & 52.995 & 23.089 & 70.621 & 44.114 & 32.387 \\
2001 & 48.659 & 21.636 & 65.863 & 42.469 & 36.279 \\
2002 & 52.136 & 16.870 & 68.974 & 35.818 & 36.754 \\
2003 & 40.091 & 18.800 & 55.139 & 37.528 & 46.533 \\
2004 & 37.321 & 23.292 & 52.698 & 44.327 & 50.826 \\
2005 & 38.379 & 30.869 & 55.850 & 57.281 & 58.523 \\
2006 & 36.985 & 40.090 & 55.783 & 72.667 & 67.965 \\
jan/07 & 38.919 & 44.446 & 59.130 & 80.389 & 91.086 \\
fev/07 & 39.458 & 44.968 & 59.940 & 81.358 & 101.070 \\
mar/07 & 40.446 & 45.517 & 61.372 & 82.472 & 109.531 \\
abr/07 & 38.773 & 46.380 & 59.291 & 83.750 & 121.830 \\
mai/07 & 40.131 & 46.997 & 61.179 & 84.915 & 136.419 \\
jun/07 & 43.938 & 47.414 & 66.165 & 85.805 & 147.101 \\
jul/07 & 48.314 & 47.715 & 71.928 & 86.773 & 155.910 \\
ago/07 & 51.621 & 48.017 & 76.368 & 87.844 & 161.097 \\
set/07 & 49.600 & 48.885 & 73.978 & 89.223 & 162.962 \\
\hline
\end{tabular}

De qualquer forma, vale notar que, com exceção dos cenários mais extremos - caracterizados por custos de default da ordem de $15 \%$ do PIB e elasticidades relativamente elevadas desse custo em relação às reservas -, o nível observado de reservas sempre se revela "excessivo" no final do período analisado. Isso parece indicar que, ainda que a política de acumulação de reservas observada entre 2006 e 2007 possa ser considerada acertada com base em alguns dos cenários descritos, já estaria na "hora de parar de comprar", conforme recomendado por Haddad (2007), ou mesmo de reduzir o montante de reservas.

O Gráfico 10 apresenta um resumo dos custos estimados do excesso de reservas, sob cada um dos Casos I a IV, para os anos de 2005 e 2006 e para o último mês analisado (setembro de 2007), em base anualizada. ${ }^{18}$ Com base nesse último mês, os custos estimados do excesso de reservas variam entre 0,04 e $0,46 \%$ do PIB, dependendo evidentemente do modelo e do cenário em questão.

18 Nos Casos III e IV, os resultados referem-se a cenários com custo de default médio de 7,5\% do PIB. 


\section{Gráfico 10 - Desperdício de recursos para diferentes modelos}

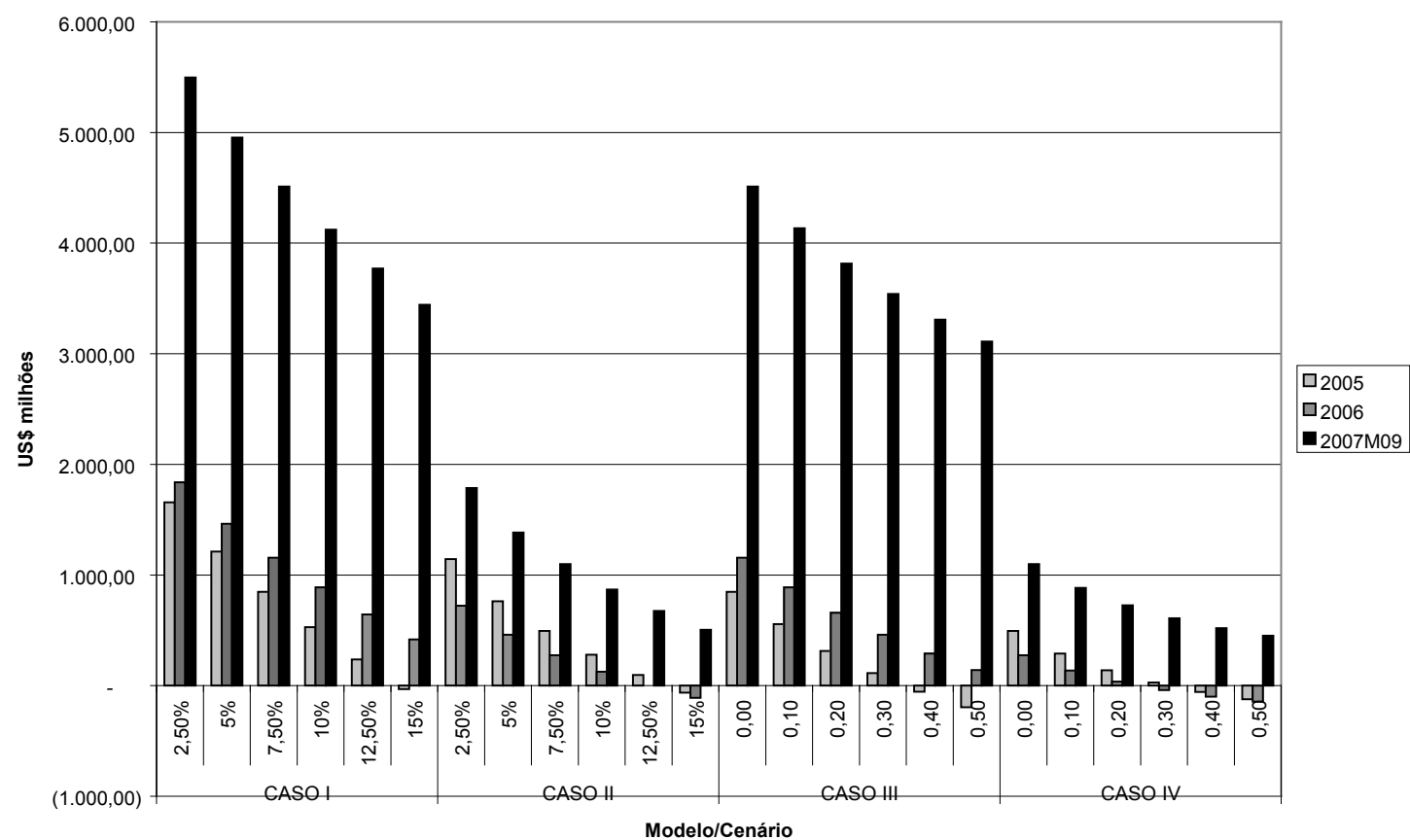

Obs.: Nos Casos III e IV, os resultados referem-se a cenários com custo de default médio de 7,5\% do PIB.

Cabe salientar que as estimativas do custo de oportunidade das reservas - e, portanto, do “desperdício de recursos” associado à manutenção de reservas em nível superior ao ótimo - variam dramaticamente entre os modelos. O Gráfico 11 ilustra essas diferenças. No Gráfico, são apresentadas as estimativas do custo de oportunidade das reservas para o período 1999-2007 sob cada um dos Casos I a IV - sendo que, nos Casos II e IV, opta-se por apresentar as estimativas para cenários "médios" no que tange à magnitude dos custos de default e sua sensibilidade em relação às reservas. Nota-se que, até 2005, o custo de oportunidade estimado revela-se substancialmente mais baixo nos Casos I e III, em que é exógeno, relativamente aos Casos II e IV, nos quais é endógeno; a partir de 2005, essa relação se inverte. Isso significa que, para uma mesma magnitude do "excesso" de reservas observadas em relação ao nível ótimo, a perda social estimada seria, até 2005, substancialmente maior nos casos II e IV, relativamente aos casos I e III; e, a partir de 2005, o oposto se verificaria. Vale notar que diferenças substanciais ocorrem também entre os casos II e IV, especialmente em cenários de turbulência externa: até o final de 2005, o modelo do caso II resulta em custo de oportunidade significativamente mais elevado do que no caso IV, que praticamente repete, para uma elasticidade de 0,3 , os valores observados do EMBI+. 


\section{Gráfico 11 - Custos de oportunidade para diferentes modelos}

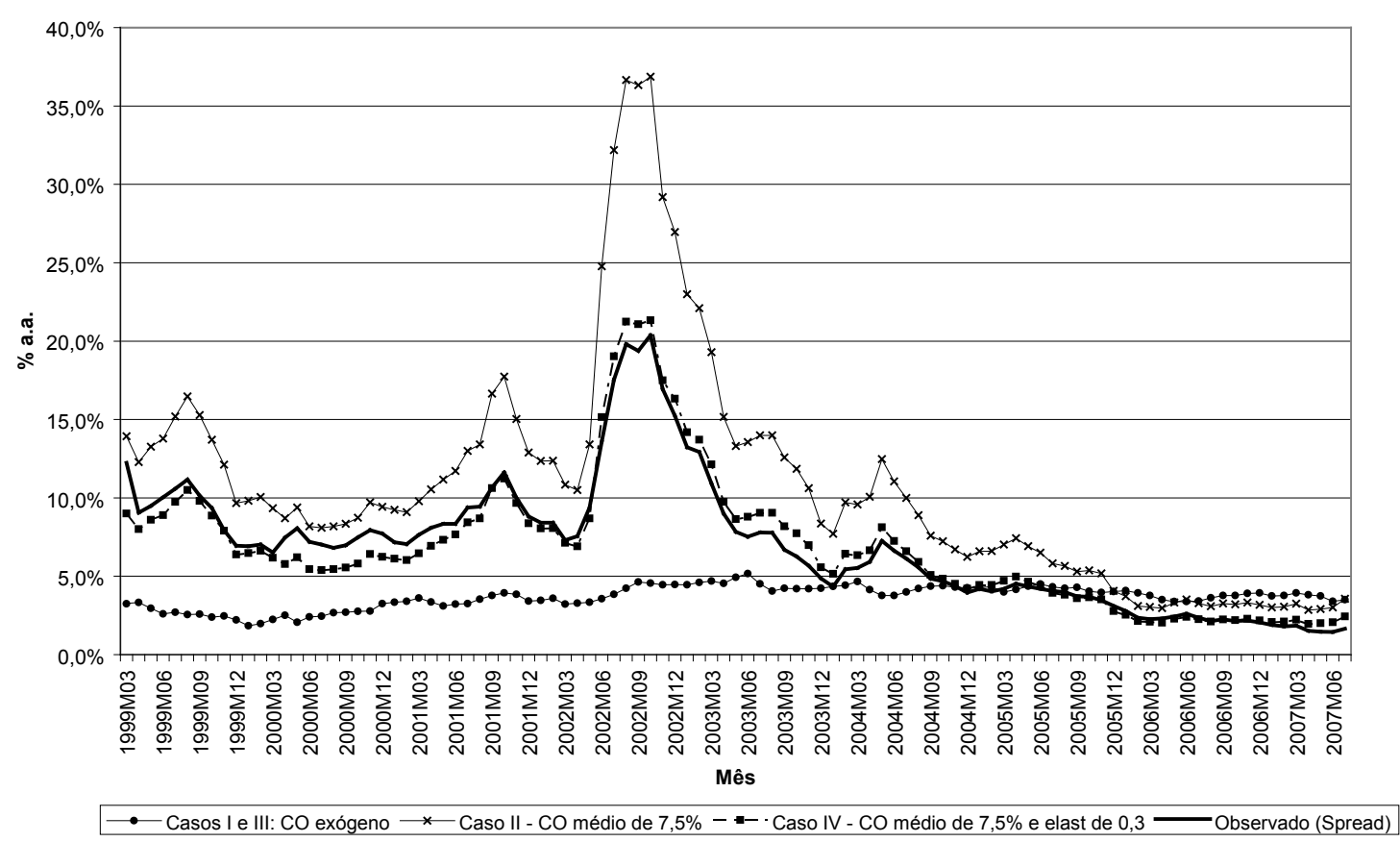

Obs.: Nos Casos III e IV, os resultados referem-se a cenários com custo de default médio de 7,5\% do PIB.

\section{CONCLUSÃO}

No presente trabalho, o nível ótimo de reservas internacionais para o Brasil foi estimado a partir de variações do modelo de Ben-Bassat e Gottlieb (1992), que consideram como benefícios das reservas a redução da probabilidade de crises, a redução do custo de captação externa e a mitigação dos custos das crises.

Os resultados obtidos sugerem que a acumulação de reservas internacionais observada no Brasil no período 1999-2007 pode ser, sob alguns dos cenários analisados, pelo menos parcialmente justificada com base nos benefícios supracitados. Entretanto, com exceção de cenários extremos para a magnitude dos custos de um default e para sua sensibilidade em relação às reservas, o nível observado de reservas sempre se revela "excessivo" no final do período em questão (setembro de 2007). Tendo em vista que o tamanho do custo de default necessário para justificar os níveis correntes de reservas parece pouco realista, pois equivaleria à combinação dos efeitos de uma crise cambial e de uma crise bancária - que, em um país com câmbio flutuante e sistema financeiro robusto, parece pouco provável -, conclui-se que, à luz do modelo, ainda que a política de acumulação de reservas observada entre 2006 e 2007 possa ser considerada acertada com base em alguns dos cenários descritos, já estaria na "hora de parar de 
comprar", ou mesmo de vender parte das reservas, sob pena de gerar perdas sociais crescentes para o País.

A análise é limitada sob vários aspectos. Primeiro, há grande incerteza quanto a parâmetros cruciais do modelo, tais como o custo de oportunidade das reservas, o custo de uma crise de default e o efeito de um maior volume de reservas sobre a probabilidade e o custo de uma crise. Todos os resultados são, evidentemente, condicionais às estimativas e hipóteses adotadas para tais parâmetros.

No que diz respeito especificamente à sensibilidade da probabilidade de crises (e do spread da dívida externa) em relação ao nível de reservas, cabe notar que a análise não considera a recuperação de recebíveis para o cálculo do spread, o que pode levar - supondo que o mercado efetivamente considere a recuperação de recebíveis para formar os spreads - a uma subestimativa dos riscos de um default.

Além disso, conforme citado anteriormente, a análise desconsidera pelo menos três questões potencialmente relevantes para o cálculo do nível "ótimo" de reservas - o possível uso da política de reservas internacionais como forma de (tentar) afetar a taxa de câmbio, o papel das reservas como "colateral" para investimentos externos (ainda que este fator esteja correlacionado com a endogeneidade do custo de captação externa) e a existência de custos fiscais associados à necessidade de esterilizar as reservas -; logo, a análise é incompleta e seus resultados devem ser interpretados com cautela. Em particular, o "excesso" de reservas observado recentemente no Brasil em relação ao nível ótimo estimado não implica, necessariamente, que a política adotada pelo Banco Central tenha sido inadequada, mas apenas que uma possível justificativa para tal política não pode basear-se unicamente nos benefícios associados à prevenção ou atenuação dos custos esperados de uma crise externa - devendo passar, possivelmente, pela consideração dos benefícios relativos à condução da política cambial ou à atração de novos investimentos externos. A análise rigorosa dessa questão requer, contudo, um esforço considerável, devendo estar baseada em um modelo que incorpore as relações de equilíbrio geral na economia e as várias inter-relações entre as políticas monetária, fiscal e cambial. Pretende-se, em artigo futuro, construir um modelo que permita investigar tais questões adequadamente.

\section{REFERÊNCIAS}

AIZENMAN, J. Financial crisis and international reserves. In: Princeton, encyclopedia of the world economy. Princeton University Press, Feb. 2007. Available at: <http://econ.ucsc.edu/Faculty/facAizenman. shtml.>

AIZENMAN, J., LEE. Financial versus monetary mercantilism-long-run view of large international reserves Hoarding. In: $12^{\circ}$ ENCONTRO DO LACEA. Bogotá, Oct 2007. 25p.

ANGARÍTA, D. F. L. Level of international reserves and exchange risk in Colombia. Revista de Economía Institucional, v. 8, n. 15, $2^{\text {nd }}$ Sem. 2006. Available at: < http://ssrn.com/abstract=948693>. 
BAHMANI-OSKOEE, M. Demand for international reserves: a survey of recent empirical studies. Applied Economics, v. 17, n. 10, Chapman and Hall, Milwalkee, July, p. 359-375, 1985.

. Oil price shocks and stability of the demand for international reserves. Journal of Macroeconomics, v. 10, p. 633-641, 1988.

.; BROWN, F. Demand for international reserves: a review article. Applied Economics, v. 34, n. 10, p. 1209-1226, (s.l), July 2002.

BARBOSA, F. H. Os custos da política do BC. Conjuntura Econômica, mar. 2007.

BARENBOIM, I. Por que o Brasil precisa de mais reservas? Valor Econômico, 22 ago. 2006.

. Transparência para a política de reservas? Valor Econômico, 13 mar. 2007.

BARRO, R. Economic growth in East Asia before and after the financial crisis. In: NBER Working Paper Series, w8330. Cambridge: National Bureau of Economic Research, June 2001.

BEN-BASSAT, A., GOTTLIEB, D. Optimal international reserves and sovereign risk. Journal of International Economics, v. 33, n. 3-4, (s.l.), p. 345-362, 1992.

. On the effect of opportunity cost on international reserve holdings. Review of Economics and Statistics, v. 74, p. 329-332, 1992a.

BIRD, G., RAJAN, R. Too much of a good thing? The adequacy of international reserves in the aftermath of crises. Oxford. The World Economy, v. 26, n. 6, p. 873-891, June 2003.

BLANCO, E.; CÓRDOBA, A. El nível optimo de reservas internacionales - el caso venezolano. Gerencia de Investigaciones Económicas del Banco Central de Venezuela. Ago. 1996. 37p. (Serie Documentos de Trabajo, 2).

BORDO, M., EICHENGREEN, B., KLINGEBIEL, D., MARTINEZ-PERIA, M. Is the crisis problem growing more severe? Economic Policy, v. 16, p. 53-82, 2001.

CALVO, G. Capital flows and capital-market crises: the simple economics of sudden stops. Journal of Applied Economics, v. 1, n. 1, p. 35-54, Nov. 1998.

CALVO, G., REINHART, C. Fear of floating. The Quarterly Journal of Economics, v. 67, n. 2, (s.l), p. 379-407, May 2002.

CALVO, G. A.; IZQUIERDO, A.; MEJÍA, L.-F. On the empirics of sudden stops: the relevance of balancesheet effects. Research Department, Inter-American Development Bank, 2004. (Working Paper, n. 509).

CAVALCANTI, M., VONBUN, C. Calculating optimal international reserves: a cautionary note on opportunity costs. In: XXII ENCONTRO DO LACEA. Bogotá, outubro, 2007. 24p.

CLARK, P. B. Demand for international reserves: a cross country analysis. Canadian Journal of Economics, v. 3, n. 1, p. 577-94, Feb. 1970.

CROCKETT, A. Control over international reserves. In: IMF Staff Papers, v. 25, n. 1. Washington DC: International Monetary Fund, Mar. 1978. p. 1-24.

DE GREGORIO, J.; LEE, J. Growth and adjustment in East Asia and Latin America. In: Central Bank of Chile Working Paper 245, 2003.

DOOLEY, P.; MICHAEL, D.; FOLKERTS-LANDAU; GARBER, P. International financial stability. Deutsche Bank, Oct. 2005. Available at: < http://econ.ucsc.edu/ mpd/Int\%20Fin\%20Stab.pdf>.

EDWARDS, S. The demand for international reserves and exchange rate adjustments: The case of LDCs, 1964-1972. Economica, v. 50. (s.l.) p. 269-280, Aug. 1983. 
. LDC foreign borrowing and default risk: an empirical investigation, 1976-80. American Economic Review, v. 74, n. 4, p. 726-734, 1984.

. On the interest-rate elasticity of the demand for international reserves: some evidence from developing countries. Journal of International Money and Finance, v. ? 4.p. 287-295, 1985.

. Thirty years of current account imbalances, current account reversals and sudden stops. In: IMF Staff Papers, n. 51, Special Issue, 2004.

EUROPEAN CENTRAL BANK - ECB. The accumulation of foreign reserves. In: Occasional Paper Series, n. 43. Frankfurt: European Central Bank, Feb. 2006. 75p.

FEDER, G.; JUST, R. E. An analysis of credit terms in the Eurodollar market. European Economic Review, v. 9, p. 221-43, 1977.

FELDSTEIN, M. A self-help guide for emerging markets. Foreign Affairs, v. 78, n. 2, (s.l.), Mar.-Apr. 1999.

FLOOD, R.; GARBER, P. Collapsing exchange rate regimes: some linear examples. Journal of International Economics, v. 17, iss. 1-2, p. 1-13, Aug. 1984.

FLOOD, R.; MARION, N. Holding international reserves in an era of high capital mobility. In: IMF Working Paper, n. 62, 2002.

FRENKEL, J. A. The demand for international reserves under pegged and exible exchange rate regimes and aspects of the economics of managed float. In: BIGMAN, D.; TAYA,T. (Ed.). The functioning of floating exchange rates: theory evidence and policy implications. Ballinger Publishing Co., 1980a. p. 169-1995.

. International reserves under pegged exchange rates and managed float. Journal of Monetary Economics, v. ? 6, p. 295-302, 1980b.

. A. International liquidity and monetary control. In: VON FURSTENBERG, G. (Ed.). International money and credit: the policy roles. International Monetary Fund, 1983. p. 65-109.

.; JOVANOVICH, B. Optimal international reserves: a stochastic framework. Economic Journal, v. 91 , p. 507-14, 1981.

FURMAN, J.; STIGLITZ, J. Economic crises: evidence and insights from East Asia. In: Brookings Papers of Economic Activity. [s.1.]: v. 0, iss. 2, p. 1-114, 1998.

GARCIA, M. Qual o nível adequado de reservas cambiais? Valor Econômico, 4 ago. 2006a.

. Reservas cambiais: debate carente de números. Valor Econômico, 1 set. 2006b.

. Dívida pública e reservas cambiais. Valor Econômico, 28 set. 2007.

GARCIA, P., SOTO, C. Large hoardings of international reserves: are they worth it? In: CABALLERO, R.; CALDERÓN, C; CÉSPEDES, L. F. (Ed.). External vulnerability and preventive policies. Santiago: Banco Central do Chile, 2006. p. 171-206.

GERENCIA DE INVESTIGACIONES ECONÓMICAS - GIE. Informe sobre los niveles de las reservas internacionales de Venezuela. In: Serie Documentos de Trabajo, 63. Banco Central de Venezuela, nov. 2004. 54p.

GOTTLIEB, D. On the determinants of a country's creditworthiness: the case of Israel. Journal of Economic Development, v. 14, p. 65-91, 1989.

GRIMES, A. International reserves under floating exchange rates: two paradoxes explained. The Economic Record, v. 69, p. 207, p. 411-15, Dec. 1993. 
GUPTA, P.; MISHRA, D.; SAHAY, R. Output response to currency crises. In: IMF Working Papers, n. 03/230. Washington, Nov. 2003. 36p.

HADDAD, C. Já é hora de parar de comprar. Valor Econômico, 20 set. 2007.

HALL, P. The bootstrap and edgeworth expansion. New York, NY: Springer-Verlag, 1992.

HABERLER, G. How important is control over international reserves? In: MUNDELL, R. A.; POLACK, J. J. (Ed.). The new international monetary system. New York, 1977. p. 111-32.

HELLER, R. Optimal international reserves. The Economic Journal, v. 76 (s.l.) 296-311, June 1966.

HELLER, R., KHAN, M. The demand for international reserves under fixed and floating exchange rates. IMF Staff Papers, Washington: International Monetary Fund, v. 25, n. 4, p. 623-649, Dec. 1978.

HUANG, G. Modeling China's demand for international reserves. Applied Financial Economics, v. 5, p. 357-66, 1995.

HUTCHISON, M.; NOY, I. How bad are twins? Output costs of currency and banking crises. Journal of Money, Credit and Banking, v. 37, iss. 4, p. 725-752, Aug. 2005. 28p, 7 charts.

INTERNATIONAL MONETARY FUND - IMF. IMF Research Bulletin, v. 5, n. 2. Washington DC, June 2004. 8p.

JEANNE, O. International reserves in emerging market countries: too much of a good thing? In: Brookings Papers on Economic Activity 1:2007, 2007. 6p.

JEANNE, O.; RANCIÉRE, R. The optimal level of international reserves for emerging market economies: formulas and applications. In: IMF Working Paper WP/06/229, Washington DC: IMF Research Department, Oct. 2006.33p.

KAMIN, S. B.; VON KLEIST, K. The evolution and determinants of emerging market credit spreads in the 1990s. In: BIS Working Paper, n. 68, 1999.

KAMINSKY, G. E C. M. REINHART. The twin crises: the causes of banking and balance-of-payments problems. American Economic Review, [s.l.], v.89, iss. 3, p. 473-500, June 1999.

KENEN, P. B.; YUDIN, E. B. The demand for international reserve. Review of Economics and Statistics, v. 47 , p. $242-50,1965$.

KRUGMAN, P. A model of balance-of-payments crises. Journal of Money, Credit, and Banking, [s.l.], v. 11, n. 3, p. 311-325, Aug. 1979.

KRUGMAN, P. Are currency crises self-fulfilling? In: BERNANKE, B. S.; ROTEMBERG, J. (Ed.). NBER Macroeconomics Annual 1996. Cambridge, MA: MIT Press, v. 11, p. 345-378, 1996.

LACERDA, A. C. O papel das reservas na crise. Valor Econômico, 2 out. 2007.

LIZONDO, J. S.; MATHIESON, D. J. The stability of the demand for international reserves. Journal of International Money and Finance, v. 6, p. 251-82, 1987.

LOUREIRO, A. S.; BARBOSA, F. H. Risk premia for emerging markets bonds: evidence from Brazilian government debt, 1996-2002. In: Central Bank of Brazil Working Paper, n. 85, May 2004. 22p.

LOPES, D. A. R. Reservas Internacionais: Proteção em Sudden Stops?. Dissertação (Mestrado) - Pontifícia Universidade Católica do Rio de Janeiro, abr. 2005. 83p.

LOYOLA, G.Acumulação de reservas internacionais tem seu preço. Valor Econômico, 18 set. 2006.

MACHLUP, F. The need for monetary reserves. Reprints in International Finance, v. 5, Princeton University: International Finance Section, 1966. 
MANASSE, P.; ROUBINI, N. Rules of thumb for sovereign debt crises. In: IMF Working Paper, n. 05/42. Washington DC: International Monetary Fund, Mar. 2005. 33p.

MIN, H. Determinants of emerging market bond spread: Do economic fundamentals matter? In: World Bank Working Paper, n. 1899. Mar. 1998. 31 p.

MONETARY AND ECONOMIC DEPARTMENT (MED) - Bank of international settlements. foreign exchange market intervention in emerging markets: motives, techniques and implications. In: BIS Papers, n. 24, Basel., May 2005. 301p.

MOREIRA, M. M.; PUGA, F. P. Como a industria brasileira financia o seu crescimento. Uma análise do Brasil pós-Real. Revista de Economia Contemporânea, n. 5/esp., p. 35-67, 2000.

NITITHANPRAPAS, I.; WILLETT, T. Classification of Exchange Rate Regimes. Claremont Graduate University. In: ENCONTRO ANUAL DA WESTERN ECONOMIC ASSOCIATION. Seattle, Jul. 2002. (Working Paper).

OBSTFELD, M. The logic of currency crises. In: NBER Working Papers Series. Cambridge, MA: National Bureau of Economic Research, p. 1-54, Feb. 1994. (Working Paper, n. 4.640)

OLIVEROS, H.; VARELA, C. Consideraciones sobre el nivel optimo de reservas internacionales. Borradores Semanales de Economía, n. 5, Banco de la República, 1994.

OREIRO, J. L.; CURADO, M. A macroeconomia do crescimento sustentado. Valor Econômico, 7 nov. 2007.

OZYILDIRIM, S.; YAMAN, B. Optimal versus adequate level of international reserves: evidence for Turkey. Applied Economics, v. 37, n. 13, (s.l.), p. 1557-1569, July 2005.

PASTORE, A. C.; PINOTTI, M. C. Acumulação de reservas e taxa de juros. Valor Econômico, 21 abr. 2007.

ROCHA, K., SIQUEIRA, R.; PINHEIRO, F.; CARVALHO, L. Spreads soberanos: liquidez, endividamento ou governança? Texto para Discussão IPEA n. 1205, ago. 2006.

SAIDI, N. The square-root law, uncertainty and international reserves under alternative regimes: Canadian experience. 1950-1976. Journal of Monetary Economics, v. 7, p. 271-90, 1981.

SILVA JUNIOR, A.; CAJUEIRO, D.; YONEYAMA, T. Dívida pública, reservas cambiais e estratégia ótima em eventos de crises financeiras. Brasília: ESAF, 2004. 75 p. In: IX PRÊMIO TESOURO NACIONAL - 2004. Ajuste Fiscal e Dívida Pública, Brasília, DF, 2004.

SILVA JR., A.; SILVA, E. D. Optimal international reserves holdings in emerging markets economies: the Brazilian case. In: ANPEC - Associação Nacional dos Centros de Pós-Graduação em Economia. Anais do XXXII Encontro Nacional de Economia 078. 2004.16p.

SOTO, C.; NAUDON, A.; LÓPEZ, E.; AGUIRRE, A. Acerca del nivel adecuado de las reservas internacionales. In: Central Bank of Chile Working Papers, n. 267. Santiago, July 2004. 46p.

VIMOLCHALAO, S. Optimal level of international reserves: the case of Thailand. In: BANK OF THAILAND MONTHLY WORKSHOP. [s.l.], Oct. 2003. Available at: < http://www.bot.or.th/BOTHomepage/DataBank/Econcond/seminar/monthly/10-3-2003-Th-i-1/vimolchalao_SYPAfinal.pdf>.

WYPLOSZ, C. Regional monetary arrangements: lessons from Europe. Graduate Institute for International Studies, 2002. Manuscrito.

. The foreign exchange reserves buildup: business as usual? In: WORKSHOP ON DEBT, FINANCE AND EMERGING ISSUES IN FINANCIAL INTEGRATION. London, Commonwealth Secretariat, Mar 2007. 17p. 